\title{
Emerging Methods for the Fabrication of Polymer Capsules
}

Jiwei Cui, Martin P. van Koeverden, Markus Müllner, Kristian Kempe, Frank Caruso*

Department of Chemical and Biomolecular Engineering, The University of Melbourne, Parkville, Victoria 3010, Australia

*Corresponding author. Tel.: +61 38344 3461; Fax: +61 383444153.

E-mail address: fcaruso@unimelb.edu.au (F. Caruso)

\begin{abstract}
:
Hollow polymer capsules are attracting increasing research interest due to their potential application as drug delivery vectors, sensors, biomimetic nano- or multi-compartment reactors and catalysts. Thus, significant effort has been directed toward tuning their size, composition, morphology, and functionality to further their application. In this review, we provide an overview of emerging techniques for the fabrication of polymer capsules, encompassing: self-assembly, layer-by-layer assembly, single step polymer adsorption, bioinspired assembly, surface polymerization, and ultrasound assembly. These techniques can be applied to prepare polymer capsules with diverse functionality and physicochemical properties, which may fulfill specific requirements in various areas. In addition, we critically evaluate the challenges associated with the application of polymer capsules in drug delivery systems.
\end{abstract}

Keywords: nanoparticles, polymer architecture, assembly, layer-by-layer, drug delivery, nanotechnology 


\section{Contents}

1. Introduction

2. Methods for polymer capsule assembly

2.1. Self-assembly

2.2. LbL assembly

2.2.1. Different layering methods

2.2.2. Assembly interactions

2.2.3. Templates and polymer building blocks

2.3. Single-step adsorption of polymers to assemble polymer capsules

2.3.1. Mesoporous silica-templated capsules

2.3.2. Bromoisobutyramide-mediated assembly

2.3.3. Polyrotaxane capsules

2.4. Bio-inspired polymer capsules

2.5. Surface and interfacial polymerization methods

2.5.1. Grafting from hard templates

2.5.2. Continuous assembly of polymers

2.5.3. Soft template polymerization methods

2.6. Ultrasonic assembly of polymer capsules

3. Applications

3.1. Biomimetic microreactors

3.2. Drug and vaccine delivery

4. Future perspectives

Acknowledgements

References 


\section{Introduction}

Polymeric capsules, containers with a structure composed of a hollow core and a polymeric shell, have shown potential application as drug carriers, microreactors, sensors, and artificial organelles [1-3]. Generally, there are two approaches to produce polymer capsules; templatefree and template-assisted techniques. The most commonly used methods are the selfassembly of block copolymers [4], which is a template-free method, and the layer-by-layer (LbL) technique [5], which makes use of a sacrificial template. In recent years, several alternative techniques have been developed to endow polymer capsules with novel and interesting properties. A plethora of different polymers can be used to tune the properties of polymeric capsules for a desired purpose. Besides (natural) biopolymers, well-established controlled polymerization and efficient post-polymerization functionalization techniques have become indispensable tools to synthesize polymers of tailored length, composition and functionality. Hence, it is now feasible to prepare polymer capsules of diverse size, composition, morphology, and properties.

In this review, we focus on the methodologies for the fabrication of polymer capsules via self-assembly and template-assisted approaches. We briefly highlight the application of polymer capsules as controlled drug and vaccine delivery vectors, and biomimetic microreactors. Emerging topics of interest, such as the assembly of capsules with different geometry (e.g., shape and size) to modulate biological responses are also discussed. 


\section{Methods for polymer capsule assembly}

\subsection{Self-assembly}

Polymersomes are synthetic vesicles comprised of amphiphilic block copolymers, that is, polymers that consist of both hydrophilic and hydrophobic blocks, and can be considered the polymer analogue of liposomes [4]. Similarly, polymersomes are spherical structures with an aqueous core which is enclosed by a bilayer membrane. However polymersomes exhibit far greater mechanical stability than natural lipid membranes $[4,6,7]$. Consequently, they hold great potential to be used in drug or gene delivery, as they are able to encapsulate or load therapeutic molecules into their core and/or the membrane compartment. Most reported polymersomes are based on diblock copolymers and triblock terpolymers (Fig. 1). However, the desire to vary membrane conformation, increase functionality or mimic the asymmetric character of biological membranes has also led to the use of rather complex multiblock copolymers, or even blends of block copolymers.

Synthetic polymers offer almost infinite options to control the structural and physicochemical properties of membranes and vesicles. While there are already excellent reviews on polymersomes and their potential applications, we focus here on their preparation and highlight the most commonly used methods for the fabrication of polymersomes.

Polymersomes are formed via self-assembly or self-organization of block copolymers. The ratio of hydrophobic to hydrophilic block is therefore of great importance. Similar to surfactants, this ratio will dictate the self-assembly into either spherical or worm-like micelles or polymersomes [9]. There are numerous studies highlighting the diversity of block copolymer assembly, their intermediate structures and potential applications [1,8,10-22]. The most commonly used preparation methods for polymersomes are solvent-switching 
techniques (solvent displacement) [23,24] and polymer rehydration techniques (solvent free approach) [6,25-27].

Solvent-switching generally describes the addition of a block selective solvent to a block copolymer solution in a good solvent for both blocks. This technique is not limited to, but mostly performed with, water as the selective solvent $[16,28]$. Whereas the hydrophilic parts of the polymer prefer contact with water, the hydrophobic parts tend to avoid and minimize contact with water and hence are attracted to each other [8]. This procedure is also referred to as 'phase inversion'. The addition of water can thereby be performed either slowly (dropwise or during dialysis) or by a fast injection to the organic solution.

Based on the same principle, it is also possible to form polymersomes directly in water. This can be achieved by dissolving an amphiphilic block copolymer directly in water (for example under the aid of sonication [29] or detergent [30,31]). Stimuli-responsive bishydrophilic block copolymers dissolved in water are reported to form polymersomes under external stimuli, such as $\mathrm{pH}$ [18,32-35], temperature [28,35-38], or light [39]. An applied stimulus is then used to render one block hydrophobic, which subsequently triggers the self-assembly into polymersomes. Often, stimuli-responsiveness is reversible, which can be used to disassemble the polymersome again, leading to the release of encapsulated or loaded substances [40].

Another commonly used method to prepare polymersomes is the rehydration of thin films of amphiphilic block copolymers. The polymers are first dissolved in an organic solvent, followed by thin film formation via solvent evaporation. The subsequent addition of water results in rehydration of the film which, in turn, swells the polymer layers and forms protrusions that detach from the surface and close to form vesicles [8]. Polymersome formation occurs purely in water and is essentially solvent-free; however, it strongly depends 
on the kinetics of the rehydration process. Faster rehydration, for example under the aid of vigorous mixing or sonication, leads to nanometer-sized vesicles.

Other methods used to produce polymersomes include oil-in-water (o/w) emulsions [40,41], water-in-oil-in-water (w/o/w) double emulsions [42-45], inkjets [46], microfluidic devices [44,47-49], and electroformation [4].

A common issue with non-templated techniques in general, and specifically with selfassembled polymersomes, is their polydispersity in size. Post-treatment, such as extrusion [50], sonication [26], or freeze-thaw cycles [26] have proved useful to homogenize polymersome size distributions. Recently, monodisperse polymer vesicles have also been produced via a template-directed approach combining photolithography and the rehydration technique [51]. By using monodispersed templates, around which the polymer coating is formed, the LbL approach produces monodisperse polymer capsules.

\subsection{LbL assembly}

In the last 20 years, the layer-by-layer (LbL) technique has attracted significant interest in the fabrication of multilayer thin films [5,52-57]. Owing to its simplicity and versatility, researchers have reported numerous materials, templates and strategies which can be applied in LbL assembly. A distinct advantage of the LbL technique is the precise control over film properties, such as thickness and morphology that can be obtained. In general, LbL assembly is suitable for the fabrication of multilayer films on planar as well as particle supports. In recent years, research has been devoted to develop methods to overcome the issues accompanied by the transition to particle templates, such as mechanical stability and aggregation. The assembly of polymers onto (sacrificial) spherical substrates yields nano- and microcapsules after removal of the template $[5,56,58]$. The multilayer structure of these 
capsules enables the combination of different properties in one system, mostly governed by the material. These systems can be rendered responsive to external stimuli or allow for the loading with different cargo [59,60], which are of interest for therapeutic delivery and microreactor applications [61-64].

In the following subchapters layering methods and driving forces for multilayer assembly on particle supports that have been reported to date are briefly summarized. Furthermore, selected examples of polymeric materials applied for LbL assembly are presented.

\subsubsection{Different layering methods}

In template-assisted assembly, films can be formed by either surface-confined polymerization (Chapter 2.5) or by depositing (multiple) layers by LbL assembly. In recent years, different techniques have been applied for the fabrication of LbL capsules, including centrifugation, filtration and electrophoretic approaches (Fig. 2). Depending on the type of polymers and templates, the technique has to be chosen carefully to allow for optimal particle coating.

Commonly, centrifugation of the particle suspension is employed to separate the free polymer from the coated particles (Fig. 2a). However, this process requires multiple centrifugation and washing steps, rendering it time-consuming and labor-intensive. Furthermore, it suffers from the necessity to sediment the coated particles, which can promote aggregation, especially for smaller-sized templates. In contrast, the sequential addition technique uses precise concentrations of the layering material to coat the particles in suspension [67]. Thus, there is no need for centrifugation; however, the precise control of all suspension components is rather complicated and does not prevent the formation of agglomerates. To overcome some of these drawbacks, other processes have been developed over the last decades. Membrane filtration (Fig. 2b) [58] as well as electrophoretic polymer assembly (EPA) (Fig. 2c) [66] represent continuous LbL processes. Both approaches allow the particles to remain suspended, 
lowering their tendency to agglomerate. In the membrane filtration approach, template particles and polymer are suspended in a stirred tank to achieve layer deposition. Free polymer is subsequently separated from coated particles by applying a pressure differential across the filter membrane while adding a washing medium. Additional layer deposition was achieved by repeatedly adding oppositely changed polymer followed by a washing step. This approach is significant because it allows large quantities microcapsules from diverse templates to be produced using an automated technique. However, appropriate selection of filter material, to prevent polymer adsorption and filter obstruction, and the speed of filter cake formation, which leads to particle aggregation and damage, are critical factors that affect the process. Alternatively, the EPA method utilizes an agarose hydrogel to suspend template particles; layer deposition is then achieved by electrophoresis of polymers through the agarose gel. This technique allows a diverse size range of particles to be layered (down to 35 $\mathrm{nm})$. However, successful layer deposition requires that the materials are mobile in electroosmotic flow, and separation of the coated particles from the immobilizing matrix requires the application of heat and centrifugation.

\subsubsection{Assembly interactions}

For the fabrication of LbL capsules, numerous interactions have been employed to date (Fig. 3) [68]. The alternate adsorption of materials through complementary interactions can be realized by three main strategies: (a) electrostatic interactions between oppositely charged polyelectrolytes [69], (b) hydrogen bonding of hydrogen bond donor and acceptor polymers [70-72], and (c) covalent bonding for direct multilayer build-up and stabilization of preformed films [73], respectively. Besides, other chemical and physical interactions have been used to assemble and/or stabilize multilayer films, including: (d) DNA hybridization [74-79], (e) stereocomplexation [80,81], (f) hydrophobic [82], and (g) host-guest interactions [83-85]. 
The variety of interactions which can be applied for the fabrication of multilayer films further demonstrates the enormous potential of LbL for the fabrication of smart delivery systems.

\subsubsection{Templates and polymer building blocks}

The choice of the template, as well as the polymer system are crucial factors for the fabrication of polymer capsules with distinct properties and, hence, applications. While the polymer system directly determines the properties of the capsules, template choice is of equal importance since the size and shape of the final capsules are mainly dependent on the templates. Suitable templates should be stable during LbL assembly and the process of template dissolution should not affect the structure and stability of the capsule shell. The most commonly used templates, along with their size range, shape, monodispersity, and the method of core removal are listed in Table 1.

As capsule wall materials, a large number of materials/polymers (Table 2) have been used. Due to this variety, capsules can be tailor-made for certain applications by simply choosing the designed material. Among the materials available, polyelectrolytes are the most frequently used polymers for the fabrication of LbL polymer capsules. In recent years, functional polymers that are able to form multilayers through different assembly interactions (Fig. 3) have been employed to assemble functional capsules. Particular attention has been focused on hydrogen bonding systems and efficient coupling reactions. For the former, hydrogen bonding donor (e.g. PMA, PGA) and acceptor (e.g. PVPON, PEG) polymers have been extensively studied because of their capability to form stable hydrogen bonding films. For covalent coupling of layers, polymers modified with, e.g., alkyne and azide groups as well as aldehyde/epoxy and amino groups, which are able to undergo copper-catalyzed azidealkyne cycloadditions (CuAAC), imine formations and ring-opening reactions, respectively, have been studied. Current research has focused on using biomolecules, such as 
carbohydrates and peptides, due to their biodegradability. A summary of selected polymer examples, and their associated interactions as described above, is provided in Table 2.

\subsection{Single-step adsorption of polymers to assemble polymer capsules}

Despite significant progress in preparing LbL capsules using templated assembly, due to precise control over the size, composition, wall thickness and functionalities, LbL assembly typically requires multiple polymer adsorption steps, which can be time and material consuming. An alternative route to prepare polymer capsules in a minimum of steps is to exploit a surface-mediated, single-step deposition of polymer onto sacrificial templates.

\subsubsection{Mesoporous silica-templated capsules}

Mesoporous particles with large surface areas are able to entrap materials for the preparation of nanostructured materials [148-150], since adsorption is a surface driven phenomenon. Recently, a general and facile approach has been reported for the fabrication of polymer capsules via the single-step adsorption of polymers in solid core/mesoporous shell (SC/MS) silica particle templates, followed by cross-linking of the polymer chains, and subsequent removal of the templates (Fig. 4) [151]. This approach proves its versatility in generating single-component capsules of synthetic polyelectrolytes (i.e., PAH), polypeptides (i.e., PLL and PGA), and polypeptide-drug conjugates (PGA-Dox). This approach offers several distinct advantages. First, it eliminates the need for multiple polymers and/or multiple polymer adsorption steps. Secondly, this method combines the versatility and benefits of the solid core particles (high stability and monodispersity) and the high loading of mesoporous shells to prepare thick-walled polymer capsules with controlled drug payload. In this technique, the size and thickness of the capsules can be controlled by the diameter of the solid core and shell thickness of the SC/MS template, respectively [152]. However, the wall thickness of the capsules is also influenced by the molecular weight of the polymers, due to 
molecular weight-dependant infiltration of polymers into the mesopores [151], which demonstrates size matching between the mesopores and polymers is critical, as small pore sizes will exclude larger molecules [153-155].

\subsubsection{Bromoisobutyramide-mediated assembly}

Film fabrication based upon the non-covalent interaction between various biopolymers and bromoisobutyramide (BrIBAM) moieties has been recently reported by Mertz et al. [156]. In this method, biopolymers were adsorbed to the surface of BrIBAM-functionalized templates, which produced biopolymer capsules following template removal (Fig. 5a). The versatility of the technique was demonstrated by forming capsules using a range of biopolymers, including the enzymes alkaline phosphatase (AP), horseradish peroxidase (HRP) and lysozyme (LYS), the antibody immunoglobulin G (IgG), the hormone insulin (INS), polypeptide poly-L-lysine (PLL), single- and double-stranded DNA (DNA $\mathrm{Ds}_{\mathrm{ss}}$ and $\mathrm{DNA}_{\mathrm{ds}}$ ), and the polysaccharide dextran (DEX) (Fig. 5b-i).

It was proposed that the adsorption of protein to the template and stabilization of the film was due to non-covalent halogen bonding between BrIBAM groups and the biopolymers [156], analogous to previously observed interactions between proteins and DNA with various bromoamide compounds [157].

Due to the moderate mechanically stability of the protein capsules fabricated using a single adsorption step, two techniques were devised to improve the robustness of BrIBAM-mediated capsules. Cross-linking of the core-shell particles with an amine reactive cross-linker, followed by core removal produced stable capsules with improved colloidal stability in comparison to non-cross-linked BrIBAM capsules [158]. Importantly, the cross-linking process did not comprise the catalytic activity of two capsule systems fabricated from enzymes, and allowed the fabrication of sub-micron sized protein capsules, which could not 
be achieved using a non-cross-linked BrIBAM adsorption process. Alternatively, mechanically stable capsules could be obtained by refunctionalization of a single layer coreshell particle with BrIBAM groups. Following this, additional film deposition was achieved by repeated protein adsorption and BrIBAM refunctionalization [128]. When the sequential adsorption process utilized the non-brominated IBAM, reduced layer buildup was observed compared to the BrIBAM case, supporting the conclusion that film assembly was due to a combined halogen and hydrogen bonding network between BrIBAM groups and protein chains.

\subsubsection{Polyrotaxane capsules}

Due to their novel material properties, the assembly of polymer nanostructures from supramolecular building blocks, in particular polymeric rotaxanes or polyrotaxanes (PRXs), is an emerging field of research. PRXs are macromolecules that consist of a non-covalent, mechanically interlocked structure of cyclic molecules threading a linear backbone axis, analogous to beads on a necklace [159-161]. Among PRX materials, cyclodextrin (CD) and PEG-derived PRXs possess several advantages compared to alternative systems, due to the low inherent cytotoxicity of CDs and PEG, as well as low cost and commercial availability. The dynamic nature of this threading/dethreading requires that the free PEG chain ends are stoppered with bulky blocking groups to produce stable PRX molecules [160,161]. Through the use of stimuli-responsive blocking groups e.g., redox or $\mathrm{pH}$, $\mathrm{PRX}$ can be engineered with degradable properties [162-164]. The non-covalent nature of the material imparts several favorable properties. For example, variation of the molecular weight of the axial component and threading degree allows the persistence length and rigidity of the PRXs to be tuned $[165,166]$. Moreover the non-covalent interaction between the cyclic and axial components allows both rotational and longitudinal movement of the cyclic component on the molecule axis. Importantly, this mobility results in improved multivalent binding interactions, due to 
the ability of the binding ligand to adopt a more favorable binding conformation, in comparison to covalent macromolecular building blocks $[160,161]$. These unique and interesting properties have led to increasing research interest into PRX building blocks.

The presence of multiple hydroxyl groups around the CD torus allows the PRXs to be readily functionalized. Using this approach, Dam and Caruso synthesized polyanion and polycation PRXs by functionalization of the $\alpha \mathrm{CD}$ hydroxyl groups with carboxyl and amino moieties respectively. These PRX polyelectrolytes were subsequently used to fabricate PRX films [162] and capsules [164] using the LbL technique. Due to the presence of a disulfide containing blocking group at the chain ends, incubation of the PRX films with the intracellular reducing agent glutathione (GSH) resulted in unblocking of the chain end, causing dethreading of the $\alpha \mathrm{CDs}$ and subsequent film degradation into $\alpha \mathrm{CD}$ and PEG components.

An alternative approach to LbL assembly, is the use of a radial assembly technique pioneered by $\mathrm{Wu}$ and $\mathrm{Li}$, in which the PRX orientation is ideally directed away from the substrate, analogous to substrate tethered polymer brushes [167]. In this example, gold nanoparticles (AuNPs) were PEG functionalized, then subsequently threaded with $\alpha \mathrm{CD}$. Following blocking of the free PEG chain end with 2,4,6-trinitrobenzene sulfonic acid (TNBS), and intermolecular covalent crosslinking between the $\alpha \mathrm{CD}$ toroids, PRX nanocapsules were obtained following AuNP etching (Fig. 6). Alternatively, Dam and Caruso demonstrated the radial assembly of PRX capsules using pre-synthesized $\alpha \mathrm{CD} / \mathrm{PEG}$ PRXs [163]. Alkyne endfunctional PRXs were grafted to the surface of azido-functional silica particles. Following cross-linking of the PRX shell with a disulfide cross-linker and silica etching, hollow PRX capsules were obtained. Use of a disulfide containing cross-linker and blocking group allowed degradation of the capsules to free PEG and $\alpha \mathrm{CD}$ upon exposure to GSH. 
In combination with their readily tunable properties, the non-covalent nature of PRX building blocks, which engenders them with unique physicochemical properties, is likely to see increasing application in the assembly of polymer nano- and microcapsules for next generation applications.

\subsection{Bio-inspired polymer capsules}

Inspired by the adhesive properties of mussel proteins, polydopamine (PDA) films can be coated on a wide range of planar substrates via covalent polymerization and non-covalent self-assembly in typically alkaline solution [168-170]. Based on this mussel-inspired catechol chemistry, PDA capsules have been prepared via single-step assembly of PDA films on silica particles, followed by template removal [171,172]. The obtained PDA capsules showed negligible toxicity. Similarly, polystyrene and $\mathrm{CaCO}_{3}$ have been used as templates for PDA capsule preparation, which can be removed by organic solvents and EDTA, respectively $[172,173]$. The $\mathrm{pH}$-dependant encapsulation and release of small molecules (e.g. methyl orange, alizarin red, and Rhodamine 6G) was observed [174]. Methyl orange and alizarin red were selectively encapsulated at low pH, whereas Rhodamine 6G was encapsulated at high $\mathrm{pH}$, due to the electrostatic interaction between capsules and dyes. In addition, different enzymes (i.e., $\alpha$-amylase, $\beta$-amylase and glucosidase) have been immobilized via physical encapsulation in the hollow capsule core, in situ entrapment within the capsule wall, and chemical attachment on the outer surface of capsules, respectively [175]. Monodisperse PDA capsules can also be obtained using dimethyldiethoxysilane (DMDES) oil-in-water emulsion droplets (Fig. 7a and b) [176]. These templates are removed with ethanol. The size and wall thickness of the PDA capsules can be easily tuned. Functional components, such as magnetic $\mathrm{Fe}_{3} \mathrm{O}_{4}$ nanoparticles, fluorescent quantum dots (CdSe/CdS), or an anticancer drug (thiocoraline), have been successfully encapsulated in PDA capsules. The cargo was preloaded into the emulsion droplets. 
Due to the reactivity of PDA films based on Michael addition or Schiff base formation, DOX has been conjugated to thiolated poly(methacrylic acid) (PMA $\mathrm{PH}_{\mathrm{SH}}$ ) with a $\mathrm{pH}$-cleavable hydrazone bond and subsequently immobilized onto PDA capsules [177]. This approach takes advantage of the facile PDA coating to form capsules and the acid-labile groups in the polymer-conjugate for sustained $\mathrm{pH}$-induced drug release. The obtained DOX-loaded PDA capsules showed improved reduction in cell viability of HeLa cancer cells, compared with free DOX under the same assay conditions. As PDA capsules are resistant to (bio)degradation, enzymatically degradable PGA was modified with dopamine and used for the continuous assembly of biodegradable capsules [178]. This approach allows for protease triggered cargo release while maintaining the one-step assembly procedure. The degradation kinetics in the presence of protease was correlated with the dopamine content of the polymers. Due to the simple approach and low cytotoxicity of PDA, the PDA capsules are expected to find widespread application in the generation of new particulate delivery systems.

\subsection{Surface and Interfacial Polymerization Methods}

In recent years, the use of surface-initiated polymerization (SIP) or 'grafting from' processes have emerged as facile and flexible routes to prepare hollow polymer capsules of diverse functionalities and properties. Controlled radical polymerization techniques such as Atom Transfer Radical Polymerization (ATRP) [179-183] and Reversible Addition-Fragmentation Chain Transfer (RAFT) [184-188] polymerization are amongst the most widely utilized techniques to prepare polymer capsules via SIP. Similar to polymer chain growth in solution, the SIP of polymer brushes proceeds via the chain growth polymerization of monomer units from an initiating group. However, in the case of SIP, the initiating group is anchored to the chosen substrate, forming surface attached polymer brushes. In comparison to 'grafting to' 
processes, which utilize physi- or chemisorption of polymer chains to a substrate to produce thin polymer films, SIP affords higher brush densities and hence thicker films [189].

\subsubsection{Grafting from hard templates}

The use of hard templates has several advantages, namely the fine control over the shape, size and monodispersity of template particles. Using polymer brushes polymerized from particulate templates, hollow capsules can be achieved via two main routes. If the grafted brush is hydrophobic, core removal and dispersion in aqueous solutions will produce freestanding capsules. However, due to the non-cross-linked nature, destabilization of the capsules occurs when the capsules are dispersed in a good solvent for the grafted polymer [190]. A more versatile approach to fabricate capsules is via cross-linking of grafted polymer brushes, either through the copolymerization of a cross-linking monomer, or via postpolymerization cross-linking reactions. Depending on the end application and desired properties, various cross-linking strategies can be used, for example UV cross-linking of poly(styrene)-grafted silica particles [191], or UV cross-linkable comonomers [192]. An interesting non-covalent cross-linking technique was recently demonstrated by Vamvakaki and coworkers, which demonstrates the first example of visible light-induced capsule degradation [193]. Using SI-ATRP, copolymer brushes containing a photosensitive spiropyran (SP)-containing monomer were grafted from $\mathrm{SiO}_{2}$ particles. Subsequent UV irradiation of the core-shell particles caused photoisomerization of the SP groups from the SP to merocyanine (MC) form, cross-linking the shell via MC $\pi$ - $\pi$ stacks. Degradation of the capsules was achieved by visible light irradiation, which caused isomerization of the MC groups back to the SP form, thus disrupting the $\pi-\pi$ stacking and capsule cross-linking.

The use of small molecule cross-linkers is also attractive, because additional stimuli responsive functionalities can be incorporated into the capsules, and allows tuning of capsule properties by varying the cross-linker size and architecture. For example, using active esters 
such as maleic anhydride, cross-linking can be achieved using bifunctional nucleophiles such as diamines [194]. Recently, Voit and coworkers synthesized dual-responsive polymer capsules via SI-RAFT polymerization of $\mathrm{pH}$-responsive ( $N, N$-diethylaminoethyl methacrylate) (DEAEMA) with a thiol reactive comonomer (PDSM) (Fig. 8) [195]. By varying the length of the dithiol cross-linker, the capsule permeability and swelling behavior in response to $\mathrm{pH}$ was tuned. In combination, these results demonstrate the tremendous versatility of controlled radical SIP polymerization techniques to produce hollow polymer capsules of diverse functionality and properties.

\subsubsection{Continuous Assembly of Polymers}

Recently, Qiao and Caruso developed a process, termed Continuous Assembly of Polymers (CAP), to assemble thin cross-linked (bio)polymer films and capsules [196]. Similar to 'grafting from' syntheses, CAP proceeds via a controlled chain-growth polymerization of polymerizable species from a surface bound initiating site. However, in contrast to 'grafting from' syntheses, which use monomers or small cross-linking species to produce surface confined brush films, CAP uses preformed polymer chains, termed macrocross-linkers, functionalized with multiple pendant polymerizable groups, to produce cross-linked films in one step (Fig. 9a). The use of pre-functionalized macrocross-linkers allows surface confined assembly of densely cross-linked (bio)polymer films not accessible via 'grafting from' approaches, for example polysaccharides and step-growth polymers [196]. Moreover, the CAP process is extremely versatile because it allows a range of controlled polymerization techniques such as ring opening metathesis polymerization (ROMP) [196-198], ATRP [199] and photoiniferter-mediated polymerization [200] to be utilized to drive CAP film assembly, to afford surface-confined films of diverse morphology and structure on both planar and particle templates. 
Of particular interest in biomedical applications is the fabrication of capsules via ATRPmediated CAP (CAP ATRP) [199]. Through judicious selection of reaction conditions, ATRP may be conducted under aqueous conditions in the presence of biomolecules such as proteins and enzymes [201,202], with minimal effect on enzymatic functionality [203,204]. This is likely to facilitate the application of $\mathrm{CAP}_{\text {ATRP }}$ for the facile assembly of advanced drug and enzyme delivery vectors.

\subsubsection{Soft template polymerization methods}

In addition to hard templates, soft templates have also been used for the preparation of polymer capsules via various polymerization methods. Recent studies have demonstrated that seeded radical copolymerization can be used to prepare polymer capsules using thermosensitive spheres (PNIPAM) as templates, which can be removed in water via dialysis below the lower critical solution temperature [205-208]. Copolymerization in liposomal bilayers has resulted in polymer nanocapsules with uniform nanopores, which have been used for the selective encapsulation and release of cargos [209-211]. Further, the use of emulsion templates for surface confined polymerizations has emerged as a versatile method to fabricate polymer nano- and microcapsules. As the literature of conventional miniemulsion techniques [212] has already been reviewed extensively [213], we concentrate here exclusively on techniques that confine polymerization or cross-linking to an emulsion interface.

Interfacial cross-linking is extremely versatile, as a range of cross-linking chemistries, and polymer functionalities can be incorporated. An early example is the work of Breitenkamp and Emrick [214]. In this case, an oil-in-water emulsion was stabilized using an amphiphilic graft copolymer, containing grafted hydrophilic PEG chains and a double bond-containing backbone. Addition of a biscyclooctene cross-linker and ruthenium catalyst caused crosslinking by ring-opening cross metathesis between the cyclooctene and backbone double bond groups. Bernard and coworkers formed glyconanocapsules by the interfacial step-growth 
polymerization of a bisazido sugar and hydrophobic alkyne [215]. Another interesting technique is the work of $\mathrm{Lu}$ and coworkers [216], which demonstrates the use of metal mediated cross-linking to synthesize functional capsules [216-219]. In one example, stabilization of an oil-in-water emulsion was achieved using a polymeric metallosurfactant, which served as a Prussian blue precursor. Addition of pyrrole, followed by iron(III), caused metal coordination polymerization of the surfactant periphery (termed miniemulsion periphery polymerization, MEPP) in addition to oxidative polymerization of pyrrole contained in the oil-core [217].

An alternative approach to surface confined cross-linking reactions is SIP from emulsion droplets stabilized by reactive polymer surfactants. This process is simply a 'grafting from' synthesis, which is conducted from the functionalized interface of an emulsion droplet instead of a functionalized hard template. An exemplary example is the work of Matyjaszewski and coworkers, who utilized surface-initiated miniemulsion ATRP to synthesize polymer nanocapsules [220,221]. Stabilization of the dispersed monomer phase was achieved using amphiphilic diblock copolymers, containing ATRP active end groups in the hydrophobic block. Incorporation of stimuli-responsive cross-linking comonomers (redox sensitive disulfide or acid sensitive acetal) allowed degradable polymer nanocapsules to be formed [221]. A novel extension of this work, termed inverse miniemulsion periphery RAFT polymerization (IMEPP) was recently reported by Utama and coworkers (Fig. 10) [222,223]. While the previously described miniemulsion techniques utilize a hydrophobic phase as template to achieve inward shell growth, the IMEPP technique uses an aqueous droplet as the template particle to achieve outward chain growth from the droplet surface. Consequently, the IMEPP technique allows proteins to be encapsulated inside the polymer capsule with no adverse effects on protein function, in contrast to methods which use a potentially denaturing organic phase as the template [222]. Due to their widespread application, modifications to 
conventional emulsion polymerization techniques are likely to find increasing application in the fabrication of hollow polymer capsules. However, a significant hurdle in comparison to hard-templated techniques, is the polydispersity of the templating emulsion droplets and hence size distribution of the capsules.

\subsection{Ultrasonic assembly of polymer capsules}

Microcapsules/microbubbles can be obtained via a sonochemical route [224]. Ashokkumar and coworkers reported the synthesis of stable air-filled LYS microcapsules in aqueous solution via emulsification followed by protein cross-linking under high-intensity ultrasound (Fig. 11a) [225]. A key factor to prepare stable air-filled LYS microcapsules is the efficient cross-linking between protein clusters at the air/water interface. To achieve this, LYS was denatured by DL-dithiothreitol to expose free thiol groups for protein cross-linking. In addition, the hydrophobic nature of the proteins is important to provide foaming properties, which is one of the requirements to produce air-filled microcapsules. After incubation with phosphate buffer or salt solution, the air inside of the microcapsules can be removed, resulting in hollow capsules. In a subsequent study, the efficiency of formation, size distribution and morphology of these microcapsules were controlled by manipulating the sonication time and power [226]. An increase in the sonication time and power led to the formation of larger microcapsules with a broader size distribution. The microcapsule wall thickness was found to decrease with an increase in the sonication power and time.

In addition to proteins, this ultrasonic technique can also be applied to thiol-containing synthetic macromolecules (i.e., PMA $\mathrm{SH}_{\mathrm{SH}}$ ) for the preparation of polymer capsules [227]. The wall thickness was controlled by the degree of cross-linking, which in turn was determined by the thiol content in the polymers. However, this technique usually results in micrometersized capsules with broad size distributions. To synthesize stable and relatively monodisperse 
nano- and microcapsules, a flow-through (FT) sonication technique was developed [228]. LYS capsules were prepared by pumping a partially denatured LYS solution through a FT horn at a defined flow rate and acoustic power (Fig. 11b). The size of the capsules was controlled by the active cavitation zone. The obtained capsules showed echogenic properties and a high loading capacity of oligonucleotides. In addition, large quantities of uniform capsules can be generated at a relatively low cost using the FT method.

\section{Applications}

\subsection{Biomimetic microreactors}

Polymer capsules in the nano- to micrometer size regime are important for a range of different applications, including catalysis, sensing, and the encapsulation and release of various substances [229]. More specifically, significant research interest is being devoted toward the use of polymer capsules as scaffolds and compartments in the fabrication of nanoand microreactor systems [2,3,230-232]. This research focus is inspired by the observation that biological cells use hierarchical, subcompartmentalized architectures to achieve precise control over a multitude of cascade reactions. These systems may be utilized to perform biomimetic spatially confined synthesis, or as a step toward artificial organelles and cells designed to reproduce lost metabolic function. Ideally, compartmentalization of enzymatic reactions has several major outcomes: protection of fragile enzymes from the exterior environment; spatial and temporal regulation of enzymatic reactions by controlling the local availability of competing substrates; and finally, increased local substrate and enzyme concentrations leading to improved reaction rates.

By variation of the polymer capsule structure, such as chemical functionality or membrane density, a diverse range of nano- and microreactor systems can be produced. For example, Vriezema et. al. fabricated a three enzyme cascade nanoreactor system using the coil-rod 
diblock copolymer poly(styrene)-b-poly(L-isocyanoalanine(2-thiophen-3-yl-ethyl)amine) (PS-PIAT) [233], and demonstrated that enzyme substrates and products could freely diffuse through the semipermeable membrane walls [234]. In contrast, Palivan and coworkers showed that incorporation of channel proteins into the membrane of poly(2methyloxazoline)- $b$-poly(dimethylsiloxane)- $b$-poly(2-methyloxazoline) (PMOx-PDMSPMOx) polymersomes was necessary to allow diffusion of enzyme substrates across the hydrophobic membrane [235]. Kroeger and coworkers also presented a polymersome model system to demonstrate particle incorporation by artificial membranes [236]. These examples highlight the critical importance of material structure on functionality and performance.

Alternatively, by incorporating a range of polymer capsule architectures into one reactor system, the physicochemical properties of one system, for example low stability, may be overcome by the other polymer capsule component. Caruso and coworkers have developed capsosomes systems, which consist of LbL polymer multi-layer capsules incorporating liposome subcompartments [140-147,230,237]. In this case, the multilayer shell provides mechanical stability and permeability while the liposomes allow encapsulation and protection of enzymes and small cargoes. This diversity of material structure and polymer capsule systems has led to them becoming widely used in nano- and microreactor assembly.

\subsection{Drug and vaccine delivery}

Due to their readily tuned size, chemistry and functionality, another major potential application of polymer capsules is in controlled drug and gene delivery [1,64,238,239]. Effective drug delivery vectors have several key requirements [240-244]: low toxicity and optional degradability; high loading capacity; triggered release mechanisms, such as pH-, enzyme-, or redox-triggered; low immunogenicity; and targeting groups to direct the vector to designated sites. Drug and therapeutic molecule loading can be achieved by several routes, including: co-assembly of polymer-drug conjugates [119,151,245]; drug post-loading by 
temporarily altering capsule permeability [246-251]; pre-loading of therapeutics to functional templates [176,252-257]; or incorporation into specific domains of the capsule [142,258,259]. Controlled drug release can be achieved using a range of external and biological stimuli [59,238,260,261], including $\mathrm{pH}[110,262]$, redox potential [263,264], and enzymatic reactivity $[113,151,265]$. In addition to control over biocompatibility, drug encapsulation, and triggered cargo release, stealth and targeting are of paramount importance for advanced delivery systems. PEGylation of polymer capsules is typically used to effectively prevent non-specific adsorption and cellular uptake [266-268]. Furthermore, targeting of specific cell types using specific targeting ligands, such as antibodies [269-272], may improve the effectiveness of drug accumulation and aid minimizing harmful off-target side effects.

Polymer capsules have also been used as carriers for antigens and adjuvants to promote adaptive responses in immune cells [273,274]. Recently, Caruso, Kent and coworkers reported the use of PMA $\mathrm{PH}_{\mathrm{SH}}$ capsules for the delivery of antigens (i.e., ovalbumin and KP9 oligopeptides) to professional antigen presenting cells, causing subsequent activation of $\mathrm{T}$ cells [275-277]. De Geest and coworkers utilized dextran sulfate/poly(L-arginine) capsules as antigen delivery vehicles to investigate the intracellular uptake, processing, and crosspresentation of encapsulated antigens in vitro and in vivo $[278,279]$. In a subsequent study, it was found that ovalbumin-loaded capsules functionalized with oligonucleotides (i.e., CpG) were superior in priming antibody responses and IFN-g-secreting Th1 and CTL responses [280]. For all the aforementioned vaccine delivery studies, polymer capsule fabrication was achieved using LbL assembly.

\section{Future perspectives}

Until now, most approaches to modulate the biological response and activity of polymer capsules have been chemistry-based; however, successful utilization of these systems in vivo 
is likely to require a multifaceted approach. Variation of capsule size, geometry and mechanical properties to modulate their biological interactions is an emerging area of study. A significant impetus to synthesize non-spherical capsules has been the recent findings that show particle geometry can have a dramatic influence upon biological interactions [281]. Recently, Shimoni et al. produced PMA $\mathrm{SH}_{\mathrm{SH}}$ hydrogel capsules on different aspect ratio silica rod templates using LbL assembly, and subsequently examined their shape-dependant cellular uptake [282]. Instead of LbL adsorption of polymers, it is also possible to polymerize around templates and produce different-shaped polymeric capsules, such as nanocubes or nanoplates [283].

Because precise control of both the size and shape of capsules using non-templated and soft templated methods often is challenging, fabrication of geometrically- and size-diverse capsules is dependent on the availability of well-defined template particles. However, conditions for removal of many of the monodisperse templates of controlled morphology that have been used to date need to be tuned to the polymer materials and intended applications to avoid any influence on polymer/material chemistry, encapsulated cargo functionality, and/or tethered receptors. The continued development of alternative templates of controlled size and morphology, which require only mild etching conditions, is important to broaden the application of polymer capsules in biomedical and other diverse applications. The mechanical behavior of soft materials is known to dramatically influence their biological interaction; therefore, elucidation of the chemical and structural parameters which govern material mechanical properties is also of significant importance [281]. Although fabrication of the next-generation of functional polymer capsules will be facilitated by the development of alternative (bio)polymer systems with multifunctionality, tunable degradability and cargo loading properties, their introduction must be accompanied by structure-property relationships which define the link between system chemistry and mechanics. Additionally, 
new chemistries which are introduced should be robust and facile, to facilitate utilization of scalable fabrication techniques which will ultimately be essential for the widespread application of polymer capsules. One such promising example is the work of Ejima et. al., who utilized the complexation between metal ions and natural polyphenols to produce thin films and capsules [284]. In this case, film deposition was achieved on a range of planar and particulate templates of varying chemistries. Furthermore, the metal-polyphenol films are formed extremely rapidly and are degradable under acidic conditions. Alternatively, in cases where submicron-sized spherical capsules are desired, the use of self-assembly or emulsiontemplated polymerization techniques may also prove highly versatile.

Although significant hurdles to widespread biological applications remain, our understanding of the importance of capsule properties, such as composition, size, shape and mechanics is rapidly increasing. These advances, coupled with the development of robust and facile techniques to fabricate polymer capsules, are creating new opportunities for the application of polymer capsules in biomimetic catalysis, drug delivery and other diverse fields.

\section{Acknowledgements}

This work was supported by the Australian Research Council under the Australian Laureate Fellowship (F.C., 120100030), Discovery Project (F.C., 130101846), and Super Science (F.C., FS110200025) schemes. J.C. is the recipient of an Australian Research Council Super Science Fellowship (FS110200025). J.C. also acknowledges the support of the Early Career Research Grant from the University of Melbourne. M.M. acknowledges the support of a McKenzie Postdoctoral Fellowship from the University of Melbourne. K.K. is grateful to the Alexander von Humboldt Foundation for a Feodor-Lynen fellowship. 


\section{References}

[1] Tanner P, Baumann P, Enea R, Onaca O, Palivan C, Meier W. Polymeric vesicles: From drug carriers to nanoreactors and artificial organelles. Acc Chem Res 2011;44:1039-1049.

[2] Lensen D, Vriezema DM, van Hest JCM. Polymeric microcapsules for synthetic applications. Macromol Biosci 2008;8:991-1005.

[3] van Dongen SFM, de Hoog H-PM, Peters RJRW, Nallani M, Nolte RJM, van Hest JCM. Biohybrid polymer capsules. Chem Rev 2009;109:6212-6274.

[4] Discher BM, Won Y-Y, Ege DS, Lee JC-M, Bates FS, Discher DE, et al. Polymersomes: Tough vesicles made from diblock copolymers. Science 1999;284:1143-1146.

[5] Caruso F, Caruso RA, Möhwald H. Nanoengineering of inorganic and hybrid hollow spheres by colloidal templating. Science 1998;282:1111-1114.

[6] Battaglia G, Ryan AJ. Bilayers and interdigitation in block copolymer vesicles. J Am Chem Soc 2005;127:8757-8764.

[7] Bermudez H, Brannan AK, Hammer DA, Bates FS, Discher DE. Molecular weight dependence of polymersome membrane structure, elasticity, and stability. Macromolecules 2002;35:8203-8208.

[8] LoPresti C, Lomas H, Massignani M, Smart T, Battaglia G. Polymersomes: Nature inspired nanometer sized compartments. J Mater Chem 2009;19:3576-3590.

[9] Bhargava P, Zheng JX, Li P, Quirk RP, Harris FW, Cheng SZD. Self-assembled polystyreneblock-poly(ethylene oxide) micelle morphologies in solution. Macromolecules 2006;39:4880-4888.

[10] Blanazs A, Armes SP, Ryan AJ. Self-assembled block copolymer aggregates: From micelles to vesicles and their biological applications. Macromol Rapid Commun 2009;30:267-277.

[11] Discher DE, Eisenberg A. Polymer vesicles. Science 2002;297:967-973.

[12] Chen L, Shen H, Eisenberg A. Kinetics and mechanism of the rod-to-vesicle transition of block copolymer aggregates in dilute solution. J Phys Chem B 1999;103:9488-9497.

[13] Förster S, Plantenberg T. From self-organizing polymers to nanohybrid and biomaterials. Angew Chem Int Ed 2002;41:688-714.

[14] Letchford K, Burt H. A review of the formation and classification of amphiphilic block copolymer nanoparticulate structures: Micelles, nanospheres, nanocapsules and polymersomes. Eur J Pharm Biopharm 2007;65:259-269.

[15] Discher DE, Ortiz V, Srinivas G, Klein ML, Kim Y, Christian D, et al. Emerging applications of polymersomes in delivery: From molecular dynamics to shrinkage of tumors. Prog Polym Sci 2007;32:838-857.

[16] Discher BM, Hammer DA, Bates FS, Discher DE. Polymer vesicles in various media. Curr Opin Colloid Interface Sci 2000;5:125-131.

[17] Discher DE, Ahmed F. Polymersomes. Annu Rev Biomed Eng 2006;8:323-341.

[18] Lim Soo P, Eisenberg A. Preparation of block copolymer vesicles in solution. J Polym Sci, Part B: Polym Phys 2004;42:923-938.

[19] Onaca O, Enea R, Hughes DW, Meier W. Stimuli-responsive polymersomes as nanocarriers for drug and gene delivery. Macromol Biosci 2009;9:129-139.

[20] Brinkhuis RP, Rutjes FPJT, van Hest JCM. Polymeric vesicles in biomedical applications. Polym Chem 2011;2:1449-1462. 
[21] Lee JS, Feijen J. Polymersomes for drug delivery: Design, formation and characterization. J Controlled Release 2012;161:473-483.

[22] Christian DA, Cai S, Bowen DM, Kim Y, Pajerowski JD, Discher DE. Polymersome carriers: From self-assembly to sirna and protein therapeutics. Eur J Pharm Biopharm 2009;71:463-474.

[23] Shen H, Eisenberg A. Block length dependence of morphological phase diagrams of the ternary system of ps-b-paa/dioxane/h2o. Macromolecules 2000;33:2561-2572.

[24] Lee HJ, Yang SR, An EJ, Kim J-D. Biodegradable polymersomes from poly(2-hydroxyethyl aspartamide) grafted with lactic acid oligomers in aqueous solution. Macromolecules 2006;39:49384940.

[25] Battaglia G, Ryan AJ. Pathways of polymeric vesicle formation. J Phys Chem B 2006;110:10272-10279.

[26] Lee JCM, Bermudez H, Discher BM, Sheehan MA, Won Y-Y, Bates FS, et al. Preparation, stability, and in vitro performance of vesicles made with diblock copolymers. Biotechnol Bioeng 2001;73:135-145.

[27] Battaglia G, Ryan AJ. Neuron-like tubular membranes made of diblock copolymer amphiphiles. Angew Chem Int Ed 2006;45:2052-2056.

[28] McCormick CL, Sumerlin BS, Lokitz BS, Stempka JE. Raft-synthesized diblock and triblock copolymers: Thermally-induced supramolecular assembly in aqueous media. Soft Matter 2008;4:1760-1773.

[29] Brown MD, Schätzlein A, Brownlie A, Jack V, Wang W, Tetley L, et al. Preliminary characterization of novel amino acid based polymeric vesicles as gene and drug delivery agents. Bioconjugate Chem 2000;11:880-891.

[30] Ruysschaert T, Sonnen AFP, Haefele T, Meier W, Winterhalter M, Fournier D. Hybrid nanocapsules: Interactions of aba block copolymers with liposomes. J Am Chem Soc 2005;127:62426247.

[31] Marsden HR, Quer CB, Sanchez EY, Gabrielli L, Jiskoot W, Kros A. Detergent-aided polymersome preparation. Biomacromolecules 2010;11:833-838.

[32] Du J, Tang Y, Lewis AL, Armes SP. Ph-sensitive vesicles based on a biocompatible zwitterionic diblock copolymer. J Am Chem Soc 2005;127:17982-17983.

[33] Rodríguez-Hernández J, Lecommandoux S. Reversible inside-out micellization of ph-responsive and water-soluble vesicles based on polypeptide diblock copolymers. J Am Chem Soc 2005;127:2026-2027.

[34] Du J, Fan L, Liu Q. Ph-sensitive block copolymer vesicles with variable trigger points for drug delivery. Macromolecules 2012;45:8275-8283.

[35] Pearson RT, Warren NJ, Lewis AL, Armes SP, Battaglia G. Effect of ph and temperature on pmpc-pdpa copolymer self-assembly. Macromolecules 2013;46:1400-1407.

[36] Li Y, Lokitz BS, McCormick CL. Thermally responsive vesicles and their structural "locking” through polyelectrolyte complex formation. Angew Chem Int Ed 2006;45:5792-5795.

[37] Qin S, Geng Y, Discher DE, Yang S. Temperature-controlled assembly and release from polymer vesicles of poly(ethylene oxide)-block- poly(n-isopropylacrylamide). Adv Mater 2006;18:2905-2909.

[38] Qiao Z-Y, Ji R, Huang X-N, Du F-S, Zhang R, Liang D-H, et al. Polymersomes from dual responsive block copolymers: Drug encapsulation by heating and acid-triggered release. Biomacromolecules 2013;14:1555-1563.

[39] Wang G, Tong X, Zhao Y. Preparation of azobenzene-containing amphiphilic diblock copolymers for light-responsive micellar aggregates. Macromolecules 2004;37:8911-8917. 
[40] Borchert U, Lipprandt U, Bilang M, Kimpfler A, Rank A, Peschka-Süss R, et al. Ph-induced release from p2vp-peo block copolymer vesicles. Langmuir 2006;22:5843-5847.

[41] Meng F, Hiemstra C, Engbers GHM, Feijen J. Biodegradable polymersomes. Macromolecules 2003;36:3004-3006.

[42] Lorenceau E, Utada AS, Link DR, Cristobal G, Joanicot M, Weitz DA. Generation of polymerosomes from double-emulsions. Langmuir 2005;21:9183-9186.

[43] Hayward RC, Utada AS, Dan N, Weitz DA. Dewetting instability during the formation of polymersomes from block-copolymer-stabilized double emulsions. Langmuir 2006;22:4457-4461.

[44] Shum HC, Zhao Y-j, Kim S-H, Weitz DA. Multicompartment polymersomes from double emulsions. Angew Chem Int Ed 2011;123:1686-1689.

[45] Perro A, Nicolet Cl, Angly J, Lecommandoux S, Le Meins J-F, Colin A. Mastering a double emulsion in a simple co-flow microfluidic to generate complex polymersomes. Langmuir 2010;27:9034-9042.

[46] Hauschild S, Lipprandt U, Rumplecker A, Borchert U, Rank A, Schubert R, et al. Direct preparation and loading of lipid and polymer vesicles using inkjets. Small 2005;1:1177-1180.

[47] Thiele J, Steinhauser D, Pfohl T, Förster S. Preparation of monodisperse block copolymer vesicles via flow focusing in microfluidics. Langmuir 2010;26:6860-6863.

[48] Kamat NP, Lee MH, Lee D, Hammer DA. Micropipette aspiration of double emulsion-templated polymersomes. Soft Matter 2011;7:9863-9866.

[49] Shum HC, Kim J-W, Weitz DA. Microfluidic fabrication of monodisperse biocompatible and biodegradable polymersomes with controlled permeability. J Am Chem Soc 2008;130:9543-9549.

[50] Schillén K, Bryskhe K, Mel'nikova YS. Vesicles formed from a poly(ethylene oxide)-poly(propylene oxide)-poly(ethylene oxide) triblock copolymer in dilute aqueous solution. Macromolecules 1999;32:6885-6888.

[51] Howse JR, Jones RAL, Battaglia G, Ducker RE, Leggett GJ, Ryan AJ. Templated formation of giant polymer vesicles with controlled size distributions. Nat Mater 2009;8:507-511.

[52] Decher G, Hong J-D. Buildup of ultrathin multilayer films by a self-assembly process: I. Consecutive adsorption of anionic and cationic bipolar amphiphiles on charged surfaces. Makromol Chem Macromol Symp 1991;46:321-327.

[53] Decher G, Hong JD. Buildup of ultrathin multilayer films by a self-assembly process: II. Consecutive adsorption of anionic and cationic bipolar amphiphiles and polyelectrolytes on charged surfaces. Berichte der Bunsengesellschaft für physikalische Chemie 1991;95:1430-1434.

[54] Decher G, Hong JD, Schmitt J. Buildup of ultrathin multilayer films by a self-assembly process: III. Consecutively alternating adsorption of anionic and cationic polyelectrolytes on charged surfaces. Thin Solid Films 1992;210-211, Part 2:831-835.

[55] Decher G. Fuzzy nanoassemblies: Toward layered polymeric multicomposites. Science 1997;277:1232-1237.

[56] Donath E, Sukhorukov GB, Caruso F, Davis SA, Möhwald H. Novel hollow polymer shells by colloid-templated assembly of polyelectrolytes. Angew Chem Int Edit 1998;37:2202-2205.

[57] Decher G, Schlenoff J. Multilayer thin films. Weinheim, Wiley-VCH.; 2003.

[58] Voigt A, Lichtenfeld H, Sukhorukov GB, Zastrow H, Donath E, Baumler H, et al. Membrane filtration for microencapsulation and microcapsules fabrication by layer-by-layer polyelectrolyte adsorption. Ind Eng Chem Res 1999;38:4037-4043.

[59] Esser-Kahn AP, Odom SA, Sottos NR, White SR, Moore JS. Triggered release from polymer capsules. Macromolecules 2011;44:5539-5553. 
[60] Johnston APR, Such GK, Caruso F. Triggering release of encapsulated cargo. Angew Chem Int Edit 2010;49:2664-2666.

[61] Boudou T, Crouzier T, Ren KF, Blin G, Picart C. Multiple functionalities of polyelectrolyte multilayer films: New biomedical applications. Adv Mater 2010;22:441-467.

[62] del Mercato LL, Rivera-Gil P, Abbasi AZ, Ochs M, Ganas C, Zins I, et al. LbL multilayer capsules: Recent progress and future outlook for their use in life sciences. Nanoscale 2010;2:458-467.

[63] De Koker S, Hoogenboom R, De Geest BG. Polymeric multilayer capsules for drug delivery. Chem Soc Rev 2012;41:2867-2884.

[64] Becker AL, Johnston APR, Caruso F. Layer-by-layer-assembled capsules and films for therapeutic delivery. Small 2010;6:1836-1852.

[65] Cui J, Hao J. Nanoengineered polymer capsules: From fabrication to applications. In Hao J (editor), Self-assembled structures: Properties and applications in solution and on surfaces. Boca Raton, CRC Press; 2010. Chapter 2.

[66] Richardson JJ, Ejima H, Lörcher SL, Liang K, Senn P, Cui J, et al. Preparation of nano- and microcapsules by electrophoretic polymer assembly. Angew Chem Int Edit 2013;52:6455-6458.

[67] Sukhorukov GB, Donath E, Lichtenfeld H, Knippel E, Knippel M, Budde A, et al. Layer-bylayer self assembly of polyelectrolytes on colloidal particles. Colloid Surface A 1998;137:253-266.

[68] Quinn JF, Johnston APR, Such GK, Zelikin AN, Caruso F. Next generation, sequentially assembled ultrathin films: Beyond electrostatics. Chem Soc Rev 2007;36:707-718.

[69] Sukhorukov GB, Donath E, Davis S, Lichtenfeld H, Caruso F, Popov VI, et al. Stepwise polyelectrolyte assembly on particle surfaces: A novel approach to colloid design. Polym Adv Technol 1998;9:759-767.

[70] Kozlovskaya V, Ok S, Sousa A, Libera M, Sukhishvili SA. Hydrogen-bonded polymer capsules formed by layer-by-layer self-assembly. Macromolecules 2003;36:8590-8592.

[71] Such GK, Johnston APR, Caruso F. Engineered hydrogen-bonded polymer multilayers: From assembly to biomedical applications. Chem Soc Rev 2011;40:19-29.

[72] Kharlampieva E, Kozlovskaya V, Sukhishvili SA. Layer-by-layer hydrogen-bonded polymer films: From fundamentals to applications. Adv Mater 2009;21:3053-3065.

[73] Bergbreiter DE, Liao K-S. Covalent layer-by-layer assembly-an effective, forgiving way to construct functional robust ultrathin films and nanocomposites. Soft Matter 2009;5:23-28.

[74] Johnston APR, Read ES, Caruso F. DNA multilayer films on planar and colloidal supports: Sequential assembly of like-charged polyelectrolytes. Nano Lett 2005;5:953-956.

[75] Johnston APR, Mitomo H, Read ES, Caruso F. Compositional and structural engineering of DNA multilayer films. Langmuir 2006;22:3251-3258.

[76] Johnston APR, Lee L, Wang Y, Caruso F. Controlled degradation of DNA capsules with engineered restriction-enzyme cut sites. Small 2009;5:1418-1421.

[77] Johnston APR, Caruso F. Exploiting the directionality of DNA: Controlled shrinkage of engineered oligonucleotide capsules. Angew Chem Int Edit 2007;46:2677-2680.

[78] Johnston APR, Caruso F. Stabilization of DNA multilayer films through oligonucleotide crosslinking. Small 2008;4:612-618.

[79] Cavalieri F, Ng SL, Mazzuca C, Jia ZF, Bulmus V, Davis TP, et al. Thin multilayer films and microcapsules containing DNA quadruplex motifs. Small 2011;7:101-111.

[80] Serizawa T, Hamada K, Akashi M. Polymerization within a molecular-scale stereoregular template. Nature 2004;429:52-55. 
[81] Kida T, Mouri M, Akashi M. Fabrication of hollow capsules composed of poly(methyl methacrylate) stereocomplex films. Angew Chem Int Edit 2006;45:7534-7536.

[82] Shchepelina O, Drachuk I, Gupta MK, Lin J, Tsukruk VV. Silk-on-silk layer-by-layer microcapsules. Adv Mater 2011;23:4655-4660.

[83] Wang ZP, Feng ZQ, Gao CY. Stepwise assembly of the same polyelectrolytes using host-guest interaction to obtain microcapsules with multiresponsive properties. Chem Mater 2008;20:4194-4199.

[84] Xiao W, Chen W-H, Zhang J, Li C, Zhuo R-X, Zhang X-Z. Design of a photoswitchable hollow microcapsular drug delivery system by using a supramolecular drug-loading approach. J Phys Chem B 2011;115:13796-13802.

[85] Li C, Luo G-F, Wang H-Y, Zhang J, Gong Y-H, Cheng S-X, et al. Host-guest assembly of phresponsive degradable microcapsules with controlled drug release behavior. J Phys Chem C 2011;115:17651-17659.

[86] Peyratout CS, Dähne L. Tailor-made polyelectrolyte microcapsules: From multilayers to smart containers. Angew Chem Int Ed 2004;43:3762-3783.

[87] Lee D, Rubner MF, Cohen RE. Formation of nanoparticle-loaded microcapsules based on hydrogen-bonded multilayers. Chem Mater 2005;17:1099-1105.

[88] Schuetz P, Caruso F. Copper-assisted weak polyelectrolyte multilayer formation on microspheres and subsequent film crosslinking. Adv Funct Mater 2003;13:929-937.

[89] Yu AM, Wang Y, Barlow E, Caruso F. Mesoporous silica particles as templates for preparing enzyme-loaded biocompatible microcapsules. Adv Mater 2005;17:1737-1741.

[90] Antipov AA, Shchukin D, Fedutik Y, Petrov AI, Sukhorukov GB, Möhwald H. Carbonate microparticles for hollow polyelectrolyte capsules fabrication. Colloid Surface A 2003;224:175-183.

[91] Volodkin DV, Larionova NI, Sukhorukov GB. Protein encapsulation via porous caco3 microparticles templating. Biomacromolecules 2004;5:1962-1972.

[92] Gaponik N, Radtchenko IL, Gerstenberger MR, Fedutik YA, Sukhorukov GB, Rogach AL. Labeling of biocompatible polymer microcapsules with near-infrared emitting nanocrystals. Nano Lett 2003;3:369-372.

[93] Donath E, Moya S, Neu B, Sukhorukov GB, Georgieva R, Voigt A, et al. Hollow polymer shells from biological templates: Fabrication and potential applications. Chem Eur J 2002;8:5481-5485.

[94] Shenoy DB, Antipov AA, Sukhorukov GB, Möhwald H. Layer-by-layer engineering of biocompatible, decomposable core-shell structures. Biomacromolecules 2003;4:265-272.

[95] Tjipto E, Cadwell KD, Quinn JF, Johnston APR, Abbott NL, Caruso F. Tailoring the interfaces between nematic liquid crystal emulsions and aqueous phases via layer-by-layer assembly. Nano Lett 2006;6:2243-2248.

[96] Priest C, Quinn A, Postma A, Zelikin AN, Ralston J, Caruso F. Microfluidic polymer multilayer adsorption on liquid crystal droplets for microcapsule synthesis. Lab Chip 2008;8:2182-2187.

[97] Shchukin DG, Kohler K, Möhwald H, Sukhorukov GB. Gas-filled polyelectrolyte capsules. Angew Chem Int Edit 2005;44:3310-3314.

[98] Tong WJ, Gao CY, Möhwald H. Single polyelectrolyte microcapsules fabricated by glutaraldehyde-mediated covalent layer-by-layer assembly. Macromol Rapid Commun 2006;27:20782083.

[99] Gao CY, Leporatti S, Moya S, Donath E, Möhwald H. Stability and mechanical properties of polyelectrolyte capsules obtained by stepwise assembly of poly(styrenesulfonate sodium salt) and poly(diallyldimethyl ammonium) chloride onto melamine resin particles. Langmuir 2001;17:34913495. 
[100] Qiu XP, Donath E, Möhwald H. Permeability of ibuprofen in various polyelectrolyte multilayers. Macromol Mater Eng 2001;286:591-597.

[101] Dai ZF, Möhwald H. Highly stable and biocompatible nafion-based capsules with controlled permeability for low-molecular-weight species. Chem-Eur J 2002;8:4751-4755.

[102] Mauser T, Déjugnat C, Sukhorukov GB. Balance of hydrophobic and electrostatic forces in the ph response of weak polyelectrolyte capsules. J Phys Chem B 2006;110:20246-20253.

[103] Mauser T, Déjugnat C, Sukhorukov GB. Reversible ph-dependent properties of multilayer microcapsules made of weak polyelectrolytes. Macromol Rapid Commun 2004;25:1781-1785.

[104] Zelikin AN, Quinn JF, Caruso F. Disulfide cross-linked polymer capsules: En route to biodeconstructible systems. Biomacromolecules 2006;7:27-30.

[105] Zelikin AN, Li Q, Caruso F. Disulfide-stabilized poly(methacrylic acid) capsules: Formation, cross-linking, and degradation behavior. Chem Mater 2008;20:2655-2661.

[106] Chong SF, Chandrawati R, Städler B, Park J, Cho J, Wang Y, et al. Stabilization of polymerhydrogel capsules via thiol-disulfide exchange. Small 2009;5:2601-2610.

[107] Chong SF, Lee JH, Zelikin AN, Caruso F. Tuning the permeability of polymer hydrogel capsules: An investigation of cross-linking density, membrane thickness, and cross-linkers. Langmuir 2011;27:1724-1730.

[108] Such GK, Tjipto E, Postma A, Johnston APR, Caruso F. Ultrathin, responsive polymer click capsules. Nano Lett 2007;7:1706-1710.

[109] Connal LA, Kinnane CR, Zelikin AN, Caruso F. Stabilization and functionalization of polymer multilayers and capsules via thiol-ene click chemistry. Chem Mater 2009;21:576-578.

[110] Liang K, Such GK, Zhu ZY, Yan Y, Lomas H, Caruso F. Charge-shifting click capsules with dual-responsive cargo release mechanisms. Adv Mater 2011;23:H273-H277.

[111] Kinnane CR, Such GK, Antequera-Garcia G, Yan Y, Dodds SJ, Liz-Marzan LM, et al. Lowfouling poly(n-vinyl pyrrolidone) capsules with engineered degradable properties. Biomacromolecules 2009;10:2839-2846.

[112] Ng SL, Such GK, Johnston APR, Antequera-Garcia G, Caruso F. Controlled release of DNA from poly(vinylpyrrolidone) capsules using cleavable linkers. Biomaterials 2011;32:6277-6284.

[113] De Geest BG, Vandenbroucke RE, Guenther AM, Sukhorukov GB, Hennink WE, Sanders NN, et al. Intracellularly degradable polyelectrolyte microcapsules. Adv Mater 2006;18:1005-1009.

[114] Huang CJ, Chang FC. Using click chemistry to fabricate ultrathin thermoresponsive microcapsules through direct covalent layer-by-layer assembly. Macromolecules 2009;42:5155-5166.

[115] Leung MKM, Such GK, Johnston APR, Biswas DP, Zhu ZY, Yan Y, et al. Assembly and degradation of low-fouling click-functionalized poly(ethylene glycol)-based multilayer films and capsules. Small 2011;7:1075-1085.

[116] Feng Z, Wang Z, Gao C, Shen J. Direct covalent assembly to fabricate microcapsules with ultrathin walls and high mechanical strength. Adv Mater 2007;19:3687-3691.

[117] Zhang YJ, Yang SG, Guan Y, Cao WX, Xu J. Fabrication of stable hollow capsules by covalent layer-by-layer self-assembly. Macromolecules 2003;36:4238-4240.

[118] Ma Y, Dong W-F, Hempenius MA, Möhwald H, Julius Vancso G. Redox-controlled molecular permeability of composite-wall microcapsules. Nat Mater 2006;5:724-729.

[119] Ochs CJ, Such GK, Yan Y, van Koeverden MP, Caruso F. Biodegradable click capsules with engineered drug-loaded multilayers. ACS Nano 2010;4:1653-1663.

[120] Ochs CJ, Such GK, Caruso F. Modular assembly of layer-by-layer capsules with tailored degradation profiles. Langmuir 2011;27:1275-1280. 
[121] Ochs CJ, Such GK, Städler B, Caruso F. Low-fouling, biofunctionalized, and biodegradable click capsules. Biomacromolecules 2008;9:3389-3396.

[122] Borodina T, Markvicheva E, Kunizhev S, Möhwald H, Sukhorukov GB, Kreft O. Controlled release of DNA from self-degrading microcapsules. Macromol Rapid Commun 2007;28:1894-1899.

[123] Zhao Q, Li B. Ph-controlled drug loading and release from biodegradable microcapsules. Nanomed Nanotechnol Biol Med 2008;4:302-310.

[124] Lee H, Jeong Y, Park TG. Shell cross-linked hyaluronic acid/polylysine layer-by-layer polyelectrolyte microcapsules prepared by removal of reducible hyaluronic acid microgel cores. Biomacromolecules 2007;8:3705-3711.

[125] Tiourina OP, Sukhorukov GB. Multilayer alginate/protamine microsized capsules: Encapsulation of alpha-chymotrypsin and controlled release study. Int J Pharmaceut 2002;242:155161.

[126] Radhakrishnan K, Tripathy J, Raichur AM. Dual enzyme responsive microcapsules simulating an "or" logic gate for biologically triggered drug delivery applications. Chem Commun 2013;49:5390-5392.

[127] Radhakrishnan K, Raichur AM. Biologically triggered exploding protein based microcapsules for drug delivery. Chem Commun 2012;48:2307-2309.

[128] Mertz D, Cui J, Yan Y, Devlin G, Chaubaroux C, Dochter A, et al. Protein capsules assembled via isobutyramide grafts: Sequential growth, biofunctionalization, and cellular uptake. ACS Nano 2012;6:7584-7594.

[129] Tong W, Gao C, Möhwald H. Ph-responsive protein microcapsules fabricated via glutaraldehyde mediated covalent layer-by-layer assembly. Colloid Polym Sci 2008;286:1103-1109.

[130] Ye C, Shchepelina O, Calabrese R, Drachuk I, Kaplan DL, Tsukruk VV. Robust and responsive silk ionomer microcapsules. Biomacromolecules 2011;12:4319-4325.

[131] Ye C, Drachuk I, Calabrese R, Dai H, Kaplan DL, Tsukruk VV. Permeability and micromechanical properties of silk ionomer microcapsules. Langmuir 2012;28:12235-12244.

[132] Georgieva R, Moya S, Hin M, Mitlohner R, Donath E, Kiesewetter H, et al. Permeation of macromolecules into polyelectrolyte microcapsules. Biomacromolecules 2002;3:517-524.

[133] Itoh Y, Matsusaki M, Kida T, Akashi M. Enzyme-responsive release of encapsulated proteins from biodegradable hollow capsules. Biomacromolecules 2006;7:2715-2718.

[134] De Geest BG, De Koker S, Immesoete K, Demeester J, De Smedt SC, Hennink WE. Selfexploding beads releasing microcarriers. Adv Mater 2008;20:3687-3691.

[135] De Geest BG, Van Camp W, Du Prez FE, De Smedt SC, Demeester J, Hennink WE. Degradable multilayer films and hollow capsules via a 'click' strategy. Macromol Rapid Commun 2008;29:1111-1118.

[136] Qiu XP, Leporatti S, Donath E, Möhwald H. Studies on the drug release properties of polysaccharide multilayers encapsulated ibuprofen microparticles. Langmuir 2001;17:5375-5380.

[137] Cui D, Jing J, Boudou T, Pignot-Paintrand I, De Koker S, De Geest BG, et al. Hydrophobic shell loading of biopolyelectrolyte capsules. Adv Mater 2011;23:H200-H204.

[138] Berth G, Voigt A, Dautzenberg H, Donath E, Möhwald H. Polyelectrolyte complexes and layerby-layer capsules from chitosan/chitosan sulfate. Biomacromolecules 2002;3:579-590.

[139] Gao L, Fei JB, Zhao J, Cui W, Cui Y, Li JB. Ph- and redox-responsive polysaccharide-based microcapsules with autofluorescence for biomedical applications. Chem-Eur J 2012;18:3185-3192.

[140] Städler B, Chandrawati R, Price AD, Chong SF, Breheney K, Postma A, et al. A microreactor with thousands of subcompartments: Enzyme-loaded liposomes within polymer capsules. Angew Chem Int Edit 2009;48:4359-4362. 
[141] Städler B, Chandrawati R, Goldie K, Caruso F. Capsosomes: Subcompartmentalizing polyelectrolyte capsules using liposomes. Langmuir 2009;25:6725-6732.

[142] Hosta-Rigau L, Städler B, Yan Y, Nice EC, Heath JK, Albericio F, et al. Capsosomes with multilayered subcompartments: Assembly and loading with hydrophobic cargo. Adv Funct Mater 2010;20:59-66.

[143] Hosta-Rigau L, Chung SF, Postma A, Chandrawati R, Städler B, Caruso F. Capsosomes with "free-floating" liposomal subcompartments. Adv Mater 2011;23:4082-4087.

[144] Hosta-Rigau L, Chandrawati R, Saveriades E, Odermatt PD, Postma A, Ercole F, et al. Noncovalent liposome linkage and miniaturization of capsosomes for drug delivery. Biomacromolecules 2010;11:3548-3555.

[145] Chandrawati R, Städler B, Postma A, Connal LA, Chong SF, Zelikin AN, et al. Cholesterolmediated anchoring of enzyme-loaded liposomes within disulfide-stabilized polymer carrier capsules. Biomaterials 2009;30:5988-5998.

[146] Chandrawati R, Hosta-Rigau L, Vanderstraaten D, Lokuliyana SA, Städler B, Albericio F, et al. Engineering advanced capsosomes: Maximizing the number of subcompartments, cargo retention, and temperature-triggered reaction. ACS Nano 2010;4:1351-1361.

[147] Chandrawati R, Chong SF, Zelikin AN, Hosta-Rigau L, Städler B, Caruso F. Degradation of liposomal subcompartments in pegylated capsosomes. Soft Matter 2011;7:9638-9646.

[148] Cui J, Yan Y, Wang Y, Caruso F. Templated assembly of ph-labile polymer-drug particles for intracellular drug delivery. Adv Funct Mater 2012;22:4718-4723.

[149] Cui J, De Rose R, Best JP, Johnston APR, Alcantara S, Liang K, et al. Mechanically tunable, self-adjuvanting nanoengineered polypeptide particles. Adv Mater 2013;25:3468-3472.

[150] Wang Y, Price AD, Caruso F. Nanoporous colloids: Building blocks for a new generation of structured materials. J Mater Chem 2009;19:6451-6464.

[151] Wang Y, Bansal V, Zelikin AN, Caruso F. Templated synthesis of single-component polymer capsules and their application in drug delivery. Nano Lett 2008;8:1741-1745.

[152] Goethals EC, Elbaz A, Lopata AL, Bhargava SK, Bansal V. Decoupling the effects of the size, wall thickness, and porosity of curcumin-loaded chitosan nanocapsules on their anticancer efficacy: Size is the winner. Langmuir 2013;29:658-666.

[153] Suzuki K, Siddiqui S, Chappell C, Siddiqui J, Ottenbrite R. Modification of porous silica particles with poly (acrylic acid). Polym Adv Technol 2000;11:92-97.

[154] Wang Y, Angelatos AS, Dunstan DE, Caruso F. Infiltration of macromolecules into nanoporous silica particles. Macromolecules 2007;40:7594-7600.

[155] Angelatos AS, Johnston APR, Wang Y, Caruso F. Probing the permeability of polyelectrolyte multilayer capsules via a molecular beacon approach. Langmuir 2007;23:4554-4562.

[156] Mertz D, Tan P, Wang Y, Goh TK, Blencowe A, Caruso F. Bromoisobutyramide as an intermolecular surface binder for the preparation of free-standing biopolymer assemblies. Adv Mater 2011;23:5668-5673.

[157] Metrangolo P, Meyer F, Pilati T, Resnati G, Terraneo G. Halogen bonding in supramolecular chemistry. Angew Chem Int Ed 2008;47:6114-6127.

[158] Mertz D, Wu H, Wong JS, Cui J, Tan P, Alles R, et al. Ultrathin, bioresponsive and drugfunctionalized protein capsules. J Mater Chem 2012;22:21434-21442.

[159] Harada A, Hashidzume A, Yamaguchi H, Takashima Y. Polymeric rotaxanes. Chem Rev 2009;109:5974-6023.

[160] Wenz G, Han B-H, Müller A. Cyclodextrin rotaxanes and polyrotaxanes. Chem Rev 2006;106:782-817. 
[161] Araki J, Ito K. Recent advances in the preparation of cyclodextrin-based polyrotaxanes and their applications to soft materials. Soft Matter 2007;3:1456-1473.

[162] Dam HH, Caruso F. Construction and degradation of polyrotaxane multilayers. Adv Mater 2011;23:3026-3029.

[163] Dam HH, Caruso F. Modular click assembly of degradable capsules using polyrotaxanes. ACS Nano 2012;6:4686-4693.

[164] Dam HH, Caruso F. Formation and degradation of layer-by-layer-assembled polyelectrolyte polyrotaxane capsules. Langmuir 2013;29:7203-7208.

[165] Zhao T, Beckham HW. Direct synthesis of cyclodextrin-rotaxanated poly(ethylene glycol)s and their self-diffusion behavior in dilute solution. Macromolecules 2003;36:9859-9865.

[166] Fleury G, Brochon C, Schlatter G, Bonnet G, Lapp A, Hadziioannou G. Synthesis and characterization of high molecular weight polyrotaxanes: Towards the control over a wide range of threaded [small alpha]-cyclodextrins. Soft Matter 2005;1:378-385.

[167] Wu Y-L, Li J. Synthesis of supramolecular nanocapsules based on threading of multiple cyclodextrins over polymers on gold nanoparticles. Angew Chem Int Ed 2009;48:3842-3845.

[168] Della Vecchia NF, Avolio R, Alfè M, Errico ME, Napolitano A, d'Ischia M. Building-block diversity in polydopamine underpins a multifunctional eumelanin-type platform tunable through a quinone control point. Adv Funct Mater 2013;23:1331-1340.

[169] Hong S, Na YS, Choi S, Song IT, Kim WY, Lee H. Non-covalent self-assembly and covalent polymerization co-contribute to polydopamine formation. Adv Funct Mater 2012;22:4711-4717.

[170] Lee H, Dellatore SM, Miller WM, Messersmith PB. Mussel-inspired surface chemistry for multifunctional coatings. Science 2007;318:426-430.

[171] Postma A, Yan Y, Wang Y, Zelikin AN, Tjipto E, Caruso F. Self-polymerization of dopamine as a versatile and robust technique to prepare polymer capsules. Chem Mater 2009;21:3042-3044.

[172] Yu B, Wang DA, Ye Q, Zhou F, Liu W. Robust polydopamine nano/microcapsules and their loading and release behavior. Chem Commun 2009:6789-6791.

[173] Zhang L, Shi J, Jiang Z, Jiang Y, Meng R, Zhu Y, et al. Facile preparation of robust microcapsules by manipulating metal-coordination interaction between biomineral layer and bioadhesive layer. ACS Appl Mater Interfaces 2011;3:597-605.

[174] Liu Q, Yu B, Ye W, Zhou F. Highly selective uptake and release of charged molecules by phresponsive polydopamine microcapsules. Macromol Biosci 2011;11:1227-1234.

[175] Zhang L, Shi J, Jiang Z, Jiang Y, Qiao S, Li J, et al. Bioinspired preparation of polydopamine microcapsule for multienzyme system construction. Green Chem 2011;13:300-306.

[176] Cui J, Wang Y, Postma A, Hao J, Hosta-Rigau L, Caruso F. Monodisperse polymer capsules: Tailoring size, shell thickness and hydrophobic cargo loading via emulsion templating. Adv Funct Mater 2010;20:1625-1631.

[177] Cui J, Yan Y, Such GK, Liang K, Ochs CJ, Postma A, et al. Immobilization and intracellular delivery of an anticancer drug using mussel-inspired polydopamine capsules. Biomacromolecules 2012;13:2225-2228.

[178] Ochs CJ, Hong T, Such GK, Cui J, Postma A, Caruso F. Dopamine-mediated continuous assembly of biodegradable capsules. Chem Mater 2011;23:3141-3143.

[179] Wang J-S, Matyjaszewski K. Controlled/"living" radical polymerization. Atom transfer radical polymerization in the presence of transition-metal complexes. J Am Chem Soc 1995;117:5614-5615.

[180] Kato M, Kamigaito M, Sawamoto M, Higashimura T. Polymerization of methyl methacrylate with the carbon tetrachloride/dichlorotris- (triphenylphosphine)ruthenium(ii)/methylaluminum 
bis(2,6-di-tert-butylphenoxide) initiating system: Possibility of living radical polymerization. Macromolecules 1995;28:1721-1723.

[181] Matyjaszewski K, Xia J. Atom transfer radical polymerization. Chem Rev 2001;101:2921-2990. [182] Kamigaito M, Ando T, Sawamoto M. Metal-catalyzed living radical polymerization. Chem Rev 2001;101:3689-3746.

[183] Ouchi M, Terashima T, Sawamoto M. Transition metal-catalyzed living radical polymerization: Toward perfection in catalysis and precision polymer synthesis. Chem Rev 2009;109:4963-5050.

[184] Chiefari J, Chong YK, Ercole F, Krstina J, Jeffery J, Le TPT, et al. Living free-radical polymerization by reversible addition-fragmentation chain transfer: The raft process. Macromolecules 1998;31:5559-5562.

[185] Moad G, Rizzardo E, Thang SH. Living radical polymerization by the raft process. Aust J Chem 2005;58:379-410.

[186] Moad G, Rizzardo E, Thang SH. Living radical polymerization by the raft process - a first update. Aust J Chem 2006;59:669-692.

[187] Moad G, Rizzardo E, Thang SH. Living radical polymerization by the raft process - a second update. Aust J Chem 2009;62:1402-1472.

[188] Moad G, Rizzardo E, Thang SH. Living radical polymerization by the raft process - a third update. Aust J Chem 2012;65:985-1076.

[189] Barbey Rl, Lavanant L, Paripovic D, Schüwer N, Sugnaux C, Tugulu S, et al. Polymer brushes via surface-initiated controlled radical polymerization: Synthesis, characterization, properties, and applications. Chem Rev 2009;109:5437-5527.

[190] Mandal TK, Fleming MS, Walt DR. Production of hollow polymeric microspheres by surfaceconfined living radical polymerization on silica templates. Chem Mater 2000;12:3481-3487.

[191] Fu GD, Shang Z, Hong L, Kang ET, Neoh KG. Preparation of cross-linked polystyrene hollow nanospheres via surface-initiated atom transfer radical polymerizations. Macromolecules 2005;38:7867-7871.

[192] Huang X, Appelhans D, Formanek P, Simon F, Voit B. Synthesis of well-defined photo-crosslinked polymeric nanocapsules by surface-initiated raft polymerization. Macromolecules 2011;44:8351-8360.

[193] Achilleos DS, Hatton TA, Vamvakaki M. Light-regulated supramolecular engineering of polymeric nanocapsules. J Am Chem Soc 2012;134:5726-5729.

[194] Blomberg S, Ostberg S, Harth E, Bosman AW, Van Horn B, Hawker CJ. Production of crosslinked, hollow nanoparticles by surface-initiated living free-radical polymerization. J Polym Sci, Part A: Polym Phys 2002;40:1309-1320.

[195] Huang X, Appelhans D, Formanek P, Simon F, Voit B. Tailored synthesis of intelligent polymer nanocapsules: An investigation of controlled permeability and ph-dependent degradability. ACS Nano 2012;6:9718-9726.

[196] Goh TK, Guntari SN, Ochs CJ, Blencowe A, Mertz D, Connal LA, et al. Nanoengineered films via surface-confined continuous assembly of polymers. Small 2011;7:2863-2867.

[197] Guntari SN, Goh TK, Blencowe A, Wong EHH, Caruso F, Qiao GG. Factors influencing the growth and topography of nanoscale films fabricated by romp-mediated continuous assembly of polymers. Polym Chem 2013;4:68-75.

[198] Guntari SN, Khin ACH, Wong EHH, Goh TK, Blencowe A, Caruso F, et al. (super)hydrophobic and multilayered amphiphilic films prepared by continuous assembly of polymers. Adv Funct Mater 2013:DOI: 10.1002/adfm.201300768. 
[199] Mertz D, Ochs CJ, Zhu Z, Lee L, Guntari SN, Such GK, et al. Atrp-mediated continuous assembly of polymers for the preparation of nanoscale films. Chem Commun 2011;47:12601-12603.

[200] Wong EHH, Guntari SN, Blencowe A, van Koeverden MP, Caruso F, Qiao GG. Phototriggered, metal-free continuous assembly of polymers for the fabrication of ultrathin films. ACS Macro Lett 2012;1:1020-1023.

[201] Sumerlin BS. Proteins as initiators of controlled radical polymerization: Grafting-from via atrp and raft. ACS Macro Lett 2011;1:141-145.

[202] Simakova A, Averick SE, Konkolewicz D, Matyjaszewski K. Aqueous arget atrp. Macromolecules 2012;45:6371-6379.

[203] Lele BS, Murata H, Matyjaszewski K, Russell AJ. Synthesis of uniform protein-polymer conjugates. Biomacromolecules 2005;6:3380-3387.

[204] Heredia KL, Bontempo D, Ly T, Byers JT, Halstenberg S, Maynard HD. In situ preparation of protein-"smart" polymer conjugates with retention of bioactivity. J Am Chem Soc 2005;127:1695516960.

[205] Weda P, Trzebicka B, Dworak A, Tsvetanov CB. Thermosensitive nanospheres of low-density core-an approach to hollow nanoparticles. Polymer 2008;49:1467-1474.

[206] Du P, Mu B, Wang Y, Liu P. Glucose and temperature dual-responsive monodispersed hollow nanospheres via facile one-pot two-step process. Mater Lett 2012;75:77-79.

[207] Chen Y, Sajjadi S. Thermosensitive capsules via a facile water-based core-removal process. Polymer 2013;54:5467-5472.

[208] Toncheva N, Tsvetanov C, Rangelov S, Trzebicka B, Dworak A. Hydroxyl end-functionalized poly(2-isopropyl oxazoline)s used as nano-sized colloidal templates for preparation of hollow polymeric nanocapsules. Polymer 2013;54:5166-5173.

[209] Dergunov SA, Pinkhassik E. Functionalization of imprinted nanopores in nanometer-thin organic materials. Angew Chem Int Ed 2008;47:8264-8267.

[210] Dergunov SA, Pinkhassik E. Synergistic co-entrapment and triggered release in hollow nanocapsules with uniform nanopores. J Am Chem Soc 2011;133:19656-19659.

[211] Kim MD, Dergunov SA, Lindner E, Pinkhassik E. Dye-loaded porous nanocapsules immobilized in a permeable polyvinyl alcohol matrix: A versatile optical sensor platform. Analytical chemistry 2012;84:2695-2701.

[212] Tiarks F, Landfester K, Antonietti M. Preparation of polymeric nanocapsules by miniemulsion polymerization. Langmuir 2001;17:908-918.

[213] Landfester K. Miniemulsion polymerization and the structure of polymer and hybrid nanoparticles. Angew Chem Int Ed 2009;48:4488-4507.

[214] Breitenkamp K, Emrick T. Novel polymer capsules from amphiphilic graft copolymers and cross-metathesis. J Am Chem Soc 2003;125:12070-12071.

[215] Roux R, Sallet L, Alcouffe P, Chambert S, Sintes-Zydowicz N, Fleury E, et al. Facile and rapid access to glyconanocapsules by cuaac interfacial polyaddition in miniemulsion conditions. ACS Macro Lett 2012;1:1074-1078.

[216] Liang G, Xu J, Wang X. Synthesis and characterization of organometallic coordination polymer nanoshells of prussian blue using miniemulsion periphery polymerization (mepp). J Am Chem Soc 2009;131:5378-5379.

[217] Ye S, Liu Y, Chen S, Liang S, McHale R, Ghasdian N, et al. Photoluminescent properties of prussian blue $(\mathrm{pb})$ nanoshells and polypyrrole (ppy)/pb core/shell nanoparticles prepared via miniemulsion (periphery) polymerization. Chem Commun 2011;47:6831-6833. 
[218] McHale R, Liu Y, Ghasdian N, Hondow NS, Ye S, Lu Y, et al. Dual lanthanide role in the designed synthesis of hollow metal coordination (prussian blue analogue) nanocages with large internal cavity and mesoporous cage. Nanoscale 2011;3:3685-3694.

[219] McHale R, Ghasdian N, Liu Y, Ward MB, Hondow NS, Wang H, et al. Prussian blue coordination polymer nanobox synthesis using miniemulsion periphery polymerization (mepp). Chem Commun 2010;46:4574-4576.

[220] Li W, Matyjaszewski K, Albrecht K, Möller M. Reactive surfactants for polymeric nanocapsules via interfacially confined miniemulsion atrp. Macromolecules 2009;42:8228-8233.

[221] Li W, Yoon JA, Matyjaszewski K. Dual-reactive surfactant used for synthesis of functional nanocapsules in miniemulsion. J Am Chem Soc 2010;132:7823-7825.

[222] Utama RH, Guo Y, Zetterlund PB, Stenzel MH. Synthesis of hollow polymeric nanoparticles for protein delivery via inverse miniemulsion periphery raft polymerization. Chem Commun 2012;48:11103-11105.

[223] Utama RH, Stenzel MH, Zetterlund PB. Inverse miniemulsion periphery raft polymerization: A convenient route to hollow polymeric nanoparticles with an aqueous core. Macromolecules 2013;46:2118-2127.

[224] Bang JH, Suslick KS. Applications of ultrasound to the synthesis of nanostructured materials. Adv Mater 2010;22:1039-1059.

[225] Cavalieri F, Ashokkumar M, Grieser F, Caruso F. Ultrasonic synthesis of stable, functional lysozyme microbubbles. Langmuir 2008;24:10078-10083.

[226] Zhou M, Cavalieri F, Ashokkumar M. Tailoring the properties of ultrasonically synthesised microbubbles. Soft Matter 2011;7:623-630.

[227] Cavalieri F, Zhou M, Caruso F, Ashokkumar M. One-pot ultrasonic synthesis of multifunctional microbubbles and microcapsules using synthetic thiolated macromolecules. Chem Commun 2011;47:4096-4098.

[228] Zhou M, Cavalieri F, Caruso F, Ashokkumar M. Confinement of acoustic cavitation for the synthesis of protein-shelled nanobubbles for diagnostics and nucleic acid delivery. ACS Macro Lett 2012;1:853-856.

[229] Wang Y, Angelatos AS, Caruso F. Template synthesis of nanostructured materials via layer-bylayer assembly. Chem Mater 2007;20:848-858.

[230] Städler B, Price AD, Chandrawati R, Hosta-Rigau L, Zelikin AN, Caruso F. Polymer hydrogel capsules: En route toward synthetic cellular systems. Nanoscale 2009;1:68-73.

[231] Chandrawati R, van Koeverden MP, Lomas H, Caruso F. Multicompartment particle assemblies for bioinspired encapsulated reactions. J Phys Chem Lett 2011;2:2639-2649.

[232] Marguet M, Bonduelle C, Lecommandoux S. Multicompartmentalized polymeric systems: Towards biomimetic cellular structure and function. Chem Soc Rev 2013;42:512-529.

[233] Vriezema DM, Hoogboom J, Velonia K, Takazawa K, Christianen PCM, Maan JC, et al. Vesicles and polymerized vesicles from thiophene-containing rod-coil block copolymers. Angew Chem Int Ed 2003;42:772-776.

[234] Vriezema DM, Garcia PML, Sancho Oltra N, Hatzakis NS, Kuiper SM, Nolte RJM, et al. Positional assembly of enzymes in polymersome nanoreactors for cascade reactions. Angew Chem Int Ed 2007;46:7378-7382.

[235] Tanner P, Onaca O, Balasubramanian V, Meier W, Palivan CG. Enzymatic cascade reactions inside polymeric nanocontainers: A means to combat oxidative stress. Chem Eur J 2011;17:45524560. 
[236] Jaskiewicz K, Larsen A, Lieberwirth I, Koynov K, Meier W, Fytas G, et al. Probing bioinspired transport of nanoparticles into polymersomes. Angew Chem Int Ed 2012;51:4613-4617.

[237] Chandrawati R, Odermatt PD, Chong S-F, Price AD, Städler B, Caruso F. Triggered cargo release by encapsulated enzymatic catalysis in capsosomes. Nano Lett 2011;11:4958-4963.

[238] Delcea M, Möhwald H, Skirtach AG. Stimuli-responsive LbL capsules and nanoshells for drug delivery. Adv Drug Delivery Rev 2011;63:730-747.

[239] Matsusaki M, Akashi M. Functional multilayered capsules for targeting and local drug delivery. Expert Opin Drug Deliv 2009;6:1207-1217.

[240] Ferrari M. Cancer nanotechnology: Opportunities and challenges. Nat Rev Cancer 2005;5:161171.

[241] Farokhzad OC, Langer R. Impact of nanotechnology on drug delivery. ACS Nano 2009;3:16-20.

[242] Shi J, Votruba AR, Farokhzad OC, Langer R. Nanotechnology in drug delivery and tissue engineering: From discovery to applications. Nano Lett 2010;10:3223-3230.

[243] Lammers T, Aime S, Hennink WE, Storm G, Kiessling F. Theranostic nanomedicine. Acc Chem Res 2011;44:1029-1038.

[244] Devadasu VR, Bhardwaj V, Kumar MN. Can controversial nanotechnology promise drug delivery? Chem Rev 2013;113:1686-1735.

[245] Yan Y, Ochs CJ, Such GK, Heath JK, Nice EC, Caruso F. Bypassing multidrug resistance in cancer cells with biodegradable polymer capsules. Adv Mater 2010;22:5398-5403.

[246] Georgieva R, Moya S, Hin M, Mitlöhner R, Donath E, Kiesewetter H, et al. Permeation of macromolecules into polyelectrolyte microcapsules. Biomacromolecules 2002;3:517-524.

[247] Sukhorukov GB, Antipov AA, Voigt A, Donath E, Möhwald H. Ph-controlled macromolecule encapsulation in and release from polyelectrolyte multilayer nanocapsules. Macromol Rapid Commun 2001;22:44-46.

[248] Tong W, Gao C, Möhwald H. Stable weak polyelectrolyte microcapsules with ph-responsive permeability. Macromolecules 2006;39:335-340.

[249] Song W, He Q, Möhwald H, Yang Y, Li J. Smart polyelectrolyte microcapsules as carriers for water-soluble small molecular drug. J Controlled Release 2009;139:160-166.

[250] Tong W, She S, Xie L, Gao C. High efficient loading and controlled release of low-molecularweight drugs by combination of spontaneous deposition and heat-induced shrinkage of multilayer capsules. Soft Matter 2011;7:8258-8265.

[251] Wang L, Chierico L, Little D, Patikarnmonthon N, Yang Z, Azzouz M, et al. Encapsulation of biomacromolecules within polymersomes by electroporation. Angew Chem Int Ed 2012;51:1112211125.

[252] Wang Y, Yan Y, Cui J, Hosta-Rigau L, Heath JK, Nice EC, et al. Encapsulation of waterinsoluble drugs in polymer capsules prepared using mesoporous silica templates for intracellular drug delivery. Adv Mater 2010;22:4293-4297.

[253] Grigoriev DO, Bukreeva T, Möhwald H, Shchukin DG. New method for fabrication of loaded micro-and nanocontainers: Emulsion encapsulation by polyelectrolyte layer-by-layer deposition on the liquid core. Langmuir 2008;24:999-1004.

[254] Price AD, Zelikin AN, Wark KL, Caruso F. A biomolecular "ship-in-a-bottle": Continuous rna synthesis within hollow polymer hydrogel assemblies. Adv Mater 2010;22:720-723.

[255] Becker AL, Orlotti NI, Folini M, Cavalieri F, Zelikin AN, Johnston APR, et al. Redox-active polymer microcapsules for the delivery of a survivin-specific sirna in prostate cancer cells. ACS Nano 2011;5:1335-1344. 
[256] Stein EW, Volodkin DV, McShane MJ, Sukhorukov GB. Real-time assessment of spatial and temporal coupled catalysis within polyelectrolyte microcapsules containing coimmobilized glucose oxidase and peroxidase. Biomacromolecules 2006;7:710-719.

[257] Marguet M, Edembe L, Lecommandoux S. Polymersomes in polymersomes: Multiple loading and permeability control. Angew Chem Int Ed 2012;51:1173-1176.

[258] Boudou T, Kharkar P, Jing J, Guillot R, Pignot-Paintrand I, Auzely-Velty R, et al. Polyelectrolyte multilayer nanoshells with hydrophobic nanodomains for delivery of paclitaxel. J Controlled Release 2012;159:403-412.

[259] Shchukina EM, Shchukin DG. LbL coated microcapsules for delivering lipid-based drugs. Adv Drug Delivery Rev 2011;63:837-846.

[260] De Geest BG, Sanders NN, Sukhorukov GB, Demeester J, De Smedt SC. Release mechanisms for polyelectrolyte capsules. Chem Soc Rev 2007;36:636-649.

[261] Skirtach AG, Yashchenok AM, Möhwald H. Encapsulation, release and applications of LbL polyelectrolyte multilayer capsules. Chem Commun 2011;47:12736-12746.

[262] Dan K, Ghosh S. One-pot synthesis of an acid-labile amphiphilic triblock copolymer and its phresponsive vesicular assembly. Angew Chem Int Ed 2013;52:7300-7305.

[263] Liang K, Such GK, Zhu Z, Dodds SJ, Johnston APR, Cui J, et al. Engineering cellular degradation of multilayered capsules through controlled cross-linking. ACS Nano 2012;6:1018610194.

[264] Sivakumar S, Bansal V, Cortez C, Chong SF, Zelikin AN, Caruso F. Degradable, surfactant-free, monodisperse polymer-encapsulated emulsions as anticancer drug carriers. Adv Mater 2009;21:18201824.

[265] Rivera-Gil P, De Koker S, De Geest BG, Parak WJ. Intracellular processing of proteins mediated by biodegradable polyelectrolyte capsules. Nano Lett 2009;9:4398-4402.

[266] Wattendorf U, Kreft O, Textor M, Sukhorukov GB, Merkle HP. Stable stealth function for hollow polyelectrolyte microcapsules through a poly(ethylene glycol) grafted polyelectrolyte adlayer. Biomacromolecules 2007;9:100-108.

[267] Heuberger R, Sukhorukov G, Vörös J, Textor M, Möhwald H. Biofunctional polyelectrolyte multilayers and microcapsules: Control of non-specific and bio-specific protein adsorption. Adv Funct Mater 2005;15:357-366.

[268] Leung MK, Hagemeyer CE, Johnston AP, Gonzales C, Kamphuis MM, Ardipradja K, et al. Bio-click chemistry: Enzymatic functionalization of pegylated capsules for targeting applications. Angew Chem Int Ed 2012;51:7132-7136.

[269] Cortez C, Tomaskovic-Crook E, Johnston AP, Radt B, Cody SH, Scott AM, et al. Targeting and uptake of multilayered particles to colorectal cancer cells. Adv Mater 2006;18:1998-2003.

[270] Cortez C, Tomaskovic-Crook E, Johnston AP, Scott AM, Nice EC, Heath JK, et al. Influence of size, surface, cell line, and kinetic properties on the specific binding of a33 antigen-targeted multilayered particles and capsules to colorectal cancer cells. ACS Nano 2007;1:93-102.

[271] Kamphuis MMJ, Johnston APR, Such GK, Dam HH, Evans RA, Scott AM, et al. Targeting of cancer cells using click-functionalized polymer capsules. J Am Chem Soc 2010;132:15881-15883.

[272] Johnston APR, Kamphuis MMJ, Such GK, Scott AM, Nice EC, Heath JK, et al. Targeting cancer cells: Controlling the binding and internalization of antibody-functionalized capsules. ACS Nano 2012;6:6667-6674.

[273] De Koker S, Lambrecht BN, Willart MA, van Kooyk Y, Grooten J, Vervaet C, et al. Designing polymeric particles for antigen delivery. Chem Soc Rev 2011;40:320-339. 
[274] Dierendonck M, De Koker S, Vervaet C, Remon JP, De Geest BG. Interaction between polymeric multilayer capsules and immune cells. J Controlled Release 2012;161:592-599.

[275] De Rose R, Zelikin AN, Johnston APR, Sexton A, Chong S-F, Cortez C, et al. Binding, internalization, and antigen presentation of vaccine-loaded nanoengineered capsules in blood. Adv Mater 2008;20:4698-4703.

[276] Sexton A, Whitney PG, Chong S-F, Zelikin AN, Johnston APR, De Rose R, et al. A protective vaccine delivery system for in vivo $t$ cell stimulation using nanoengineered polymer hydrogel capsules. ACS Nano 2009;3:3391-3400.

[277] Chong S-F, Sexton A, De Rose R, Kent SJ, Zelikin AN, Caruso F. A paradigm for peptide vaccine delivery using viral epitopes encapsulated in degradable polymer hydrogel capsules. Biomaterials 2009;30:5178-5186.

[278] De Koker S, De Geest BG, Singh SK, De Rycke R, Naessens T, Van Kooyk Y, et al. Polyelectrolyte microcapsules as antigen delivery vehicles to dendritic cells: Uptake, processing, and cross-presentation of encapsulated antigens. Angew Chem Int Ed 2009;48:8485-8489.

[279] De Geest BG, Willart MA, Hammad H, Lambrecht BN, Pollard C, Bogaert P, et al. Polymeric multilayer capsule-mediated vaccination induces protective immunity against cancer and viral infection. ACS Nano 2012;6:2136-2149.

[280] De Geest BG, Willart MA, Lambrecht BN, Pollard C, Vervaet C, Remon JP, et al. Surfaceengineered polyelectrolyte multilayer capsules: Synthetic vaccines mimicking microbial structure and function. Angew Chem Int Ed 2012;51:3862-3866.

[281] Best JP, Yan Y, Caruso F. The role of particle geometry and mechanics in the biological domain. Adv Healthcare Mater 2012;1:35-47.

[282] Shimoni O, Yan Y, Wang Y, Caruso F. Shape-dependent cellular processing of polyelectrolyte capsules. ACS Nano 2012;7:522-530.

[283] Daming C, Haibing X, Hardy Sze On C. Fabrication of polymeric hollow nanospheres, hollow nanocubes and hollow plates. Nanotechnology 2006;17:1661-1667.

[284] Ejima H, Richardson JJ, Liang K, Best JP, van Koeverden MP, Such GK, et al. One-step assembly of coordination complexes for versatile film and particle engineering. Science 2013;341:154-157. 


\section{Tables}

Table 1. Templates used for the fabrication of polymer capsules. Adapted with permission from Ref. [86]. Copyright 2004 WILEY-VCH Verlag GmbH \& Co. KGaA.

\begin{tabular}{llllll}
\hline Template & Size $(\boldsymbol{\mu m})$ & Shape & Monodispersity & Core Removal & Ref \\
\hline Melamine formaldehyde & $0.3-12$ & Spherical & Very high & $\mathrm{HCl}(0.1 \mathrm{M})$ & {$[56]$} \\
Polystyrene & $0.1-10$ & Spherical & Very high & THF, DMF & {$[87]$} \\
$\mathrm{SiO}_{2}$ & $0.03-100$ & Spherical, & High - very high & $\mathrm{HF} / \mathrm{NH}_{4} \mathrm{~F}$ & {$[88,89]$} \\
(solid/porous) & & different aspect ratios & & & \\
$\mathrm{CaCO}_{3} / \mathrm{MnCO}_{3}$ & $2-10$ & Spherical & Medium & EDTA & {$[90-92]$} \\
Red blood cell & $4-8$ & Discocytes & High & NaClO $(\mathrm{pH} \approx 12)$ & {$[93,94]$} \\
Emulsion & $0.3-100$ & Spherical & Low & Organic solvent & {$[95,96]$} \\
Bubble & $1-20$ & Spherical & Low & N/A & {$[97]$} \\
\hline
\end{tabular}


Table 2. Selected polymers and their respective modifications applied for the fabrication of

LbL capsules (a: electrostatic, b: hydrogen-bonding, c: covalent, d: DNA hybridization, e: stereocomplexation, f: hydrophobic interactions, g: host-guest interactions).

\begin{tabular}{|c|c|c|c|c|}
\hline & Polymer & Modification (chemistry) & Interaction & Reference \\
\hline & & synthetic polymers & & \\
\hline 01 & poly(styrene sulfonate) sodium salt (PSS) & & $a$ & [56] \\
\hline \multirow[t]{3}{*}{02} & poly(allylamine) (PAH) & & a & [56] \\
\hline & & (glutaraldehyde) & c & [98] \\
\hline & & $\beta$-cyclodextrin/ferrocene & g & [83] \\
\hline 03 & poly(diallyldimethylammonium) chloride & & a & [99] \\
\hline & (PDADMAC) & & & \\
\hline 04 & poly(ethyleneimine) (PEI) & & a & [100] \\
\hline 05 & Nafion/Fe ${ }^{3+}$ & & a & [101] \\
\hline 06 & poly(4-vinylpyridine) (P4VP) & & a & {$[100,102]$} \\
\hline \multirow[t]{6}{*}{07} & poly(meth)acrylic acid (PMA/PAA) & & a & [103] \\
\hline & & cysteamine (disulfide) & $\mathrm{b}$ & {$[104,105]$} \\
\hline & & PDS $^{\mathrm{a}}$ (disulfide) & $\mathrm{b}$ & {$[106,107]$} \\
\hline & & alkyne/azide (CuAAC) & b, c & [108] \\
\hline & & alkene (thiol-ene) & $\mathrm{b}$ & [109] \\
\hline & & azobenzene & g & [84] \\
\hline 08 & poly(2-diisopropylaminoethyl methacrylate) & alkyne (CuAAC) & $\mathrm{b}$ & [110] \\
\hline & (PDPA) & & & \\
\hline 09 & poly( $N$-vinylpyrrolidone) (PVPON) & alkyne (CuAAC) & $\mathrm{b}$ & {$[111,112]$} \\
\hline \multirow[t]{3}{*}{10} & poly(hydroxy-propylmethacrylamide) & dimethylaminoethyl & a & [113] \\
\hline & (PHPMA) & (hydrolytically cleavable linker) & & \\
\hline & & oligonucleotide & d & [79] \\
\hline 11 & poly( $N$-isopropylacrylamide) (PNIPAM) & alkyne, azide (CuAAC) & c & [114] \\
\hline \multirow[t]{3}{*}{12} & poly(diethylene glycol methacrylate- $r$ - & alkyne (CuAAC) & $\mathrm{b}$ & [115] \\
\hline & oligoethylene glycol methacrylate) (P(DEGMA- & & & \\
\hline & $r$-OEGMA) & & & \\
\hline 13 & poly(methyl methacrylate) (PMMA) & isotactic/syndiotactic & e & [81] \\
\hline 14 & poly(glycidyl methacrylate) (PGMA) & (ring-opening) & c & [116] \\
\hline 15 & $\mathrm{NDR} / \mathrm{MPR}^{\mathrm{b}}$ & aryl diazonium (azo coupling) & c & [117] \\
\hline 16 & poly(ferrocenylsilane) (PFS) & sulfonate/ethyl dimethyl ammonium & a & [118] \\
\hline
\end{tabular}




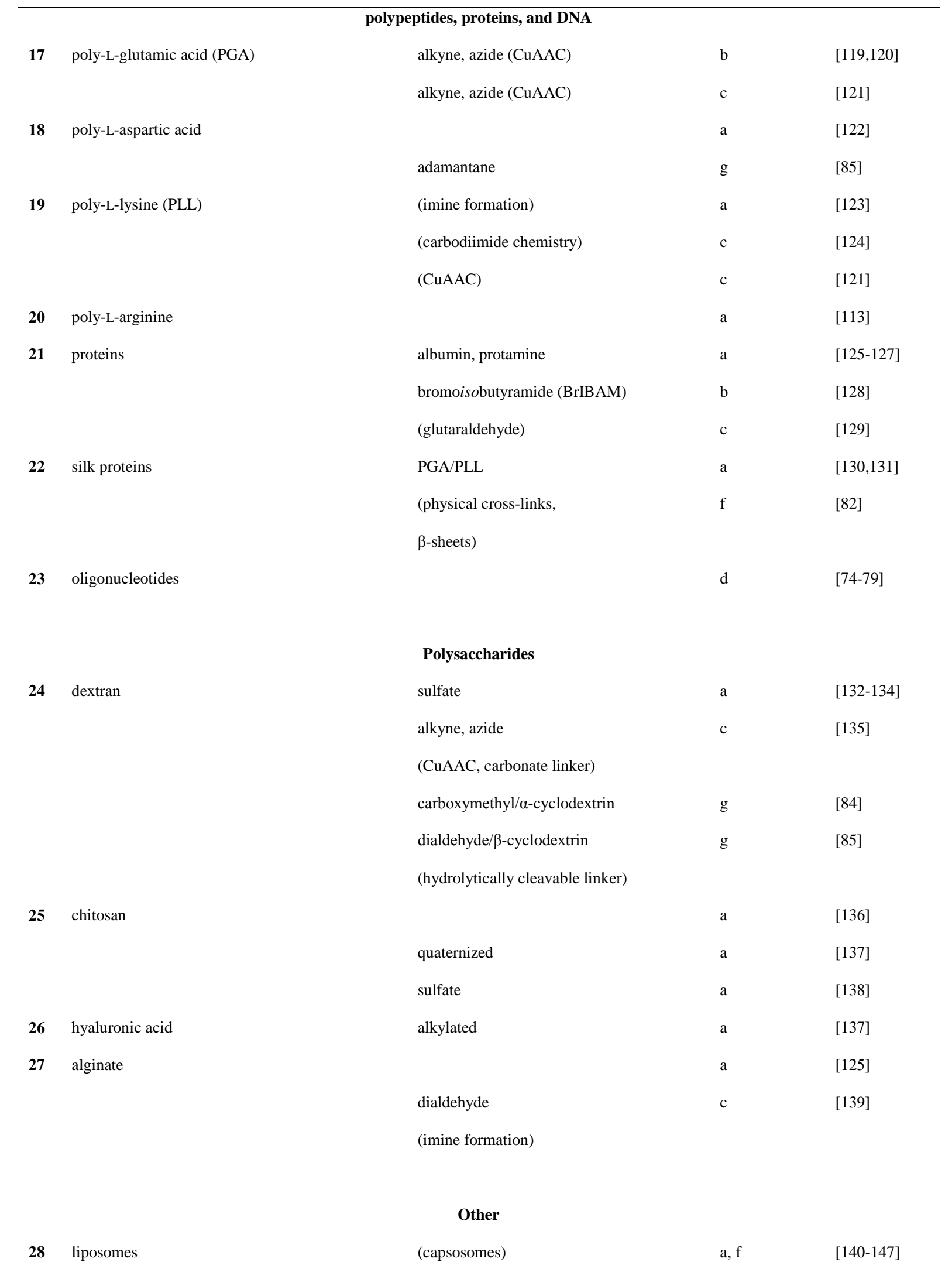

${ }^{\mathrm{a}}$ Pyridine dithioethylamine

${ }^{\mathrm{b}} \mathrm{N}$-methyl-2-nitro-diphenylamine-4-diazoresin/m-methylphenol-formaldehyde resin 


\section{Figure Captions}

Fig. 1. (a) Schematic diagram of the structure of a polymersome in water, showing the hydrophobic membrane (red) and hydrophilic corona (blue). Polymersome membrane conformation formed by self-assembly of (b) AB diblock and (c) ABA triblock copolymers, and (d) ABC triblock terpolymers. Adapted with permission from Ref. [8]. Copyright 2009 The Royal Society of Chemistry.

Fig. 2. Schematic representation of LbL assembly of polymer capsules with different approaches: (a) Centrifugation; (b) Filtration; and (c) Electrophoretic polymer assembly. Adapted with permission from Ref. [66]. Copyright 2013 WILEY-VCH Verlag GmbH \& Co. KGaA.

Fig. 3. Different polymer interactions for the assembly of multilayer capsules (centre). Interactions clockwise from left: (a) electrostatic; (b) hydrogen bonding; (c) covalent bonding; (d) DNA hybridization; (e) stereocomplexation; (f) hydrophobic; and (g) host-guest interactions.

Fig. 4. (a) Schematic representation of the preparation of single-component polymer capsules by using SC/MS particles as templates. (b) SEM image of PAH nanocapsules. (c) TEM image of PLL nanocapsules. (d) TEM and (e) fluorescence microscopy images of PGA-Dox nanocapsules. Adapted with permission from Ref. [151]. Copyright 2008 American Chemical Society.

Fig. 5. (a) Single-step adsorption of a biopolymer (e.g., polypeptide, protein, nucleic acid or polysaccharide) from aqueous solution onto BrIBAM-modified silica templates followed by template removal yields the formation of free-standing biopolymer capsules. Fluorescence microscopy images of (b) AP, (c) HRP, (d) LYS, (e) IgG, (f) INS, (g) PLL, (h) DNA ds, and (i) DEX capsules. RITC- or FITC-labeling results in red and green fluorescence, respectively. 
Scale bars are $5 \mu \mathrm{m}$. Adapted with permission from Ref. [156]. Copyright 2011 WILEYVCH Verlag GmbH \& Co. KGaA.

Fig. 6. Assembly of PRX nanocapsules by radial assembly from PEG functionalized AuNPs. Crosslinking was achieved by activation of the $\alpha \mathrm{CD}$ hydroxyl groups followed by reaction with PEI. Adapted with permission from Ref. [167]. Copyright 2009 WILEY-VCH Verlag GmbH \& Co. KGaA.

Fig. 7. (a) Schematic representation of the encapsulation of hydrophobic species in PDA capsules using DMDES emulsion templates. (b) An enlarged schematic of a loaded PDA capsule. Adapted with permission from Ref. [176]. Copyright 2010 WILEY-VCH Verlag GmbH \& Co. KGaA.

Fig. 8. Schematic for the assembly of dual-responsive (pH and redox) polymer capsules via SI-RAFT polymerization from aminated silica templates. Reproduced with permission from Ref. [195]. Copyright 2012 American Chemical Society.

Fig. 9. (a) Schematic of film formation via the $\mathrm{CAP}_{\mathrm{ROMP}}$ process on a planar substrate. Surface initiator functionalization is achieved using catalyst $\mathbf{1}$ followed by the $\mathrm{CAP}_{\mathrm{ROMP}}$ reaction with either $\mathbf{P 1}, \mathbf{P} 2$ or $\mathbf{P} 3$ macrocross-linkers. $\mathbf{X}^{\prime}$ represents the interlayer spacing. (b) Schematic of capsule formation via $\mathrm{CAP}_{\mathrm{ROMP}}$. Increased layer build-up was achieved by reinitiation of the polymer film with catalyst $\mathbf{1}$ followed by a CAP $\mathrm{ROMP}_{\mathrm{M}}$ assembly step. This process was repeated until the desired film thickness was achieved followed by core removal. Adapted with permission from Ref. [196]. Copyright 2011 WILEY-VCH Verlag GmbH \& Co. KGaA. 
Fig. 10. Schematic of hollow protein-loaded polymer capsule assembly by IMEPP using poly(HPMA-b-MMA) as the surface-active RAFT agent. Reproduced with permission from Ref. [222]. Copyright 2012 The Royal Society of Chemistry.

Fig. 11. (a) Proposed mechanism for the formation of disulfide cross-linked air-filled polymer microcapsules. (1) Emulsification of the amphiphilic polymer nanoaggregates induced by high energy ultrasound. (2) Diffusion of the polymer nanoaggregates to the interface. (3) Disulfide bridge formation between polymer nanoaggregates adsorbed at the air/water interfaces. Adapted with permission from Ref. [225]. Copyright 2008 American Chemical Society. (b) Schematic representation of the formation of microcapsules using the flow through sonication cell. Adapted with permission from Ref. [228]. Copyright 2012 American Chemical Society. 


\section{Figures}

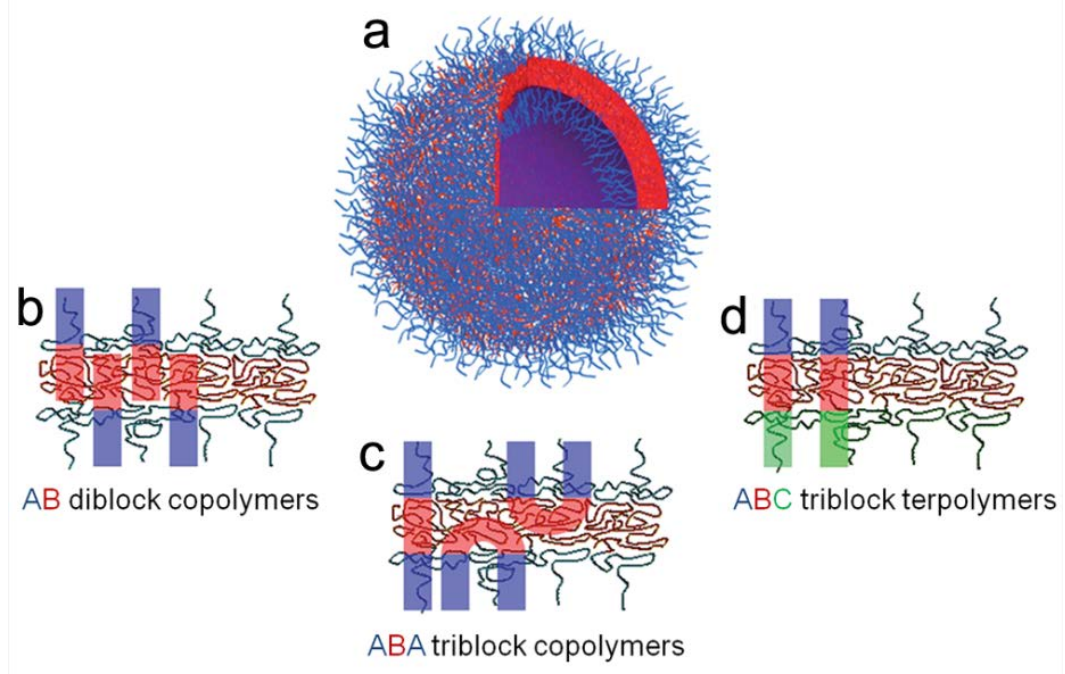

Fig. 1. (a) Schematic diagram of the structure of a polymersome in water, showing the hydrophobic membrane (red) and hydrophilic corona (blue). Polymersome membrane conformation formed by self-assembly of (b) AB diblock and (c) ABA triblock copolymers, and (d) ABC triblock terpolymers. Adapted with permission from Ref. [8]. Copyright 2009 The Royal Society of Chemistry. 

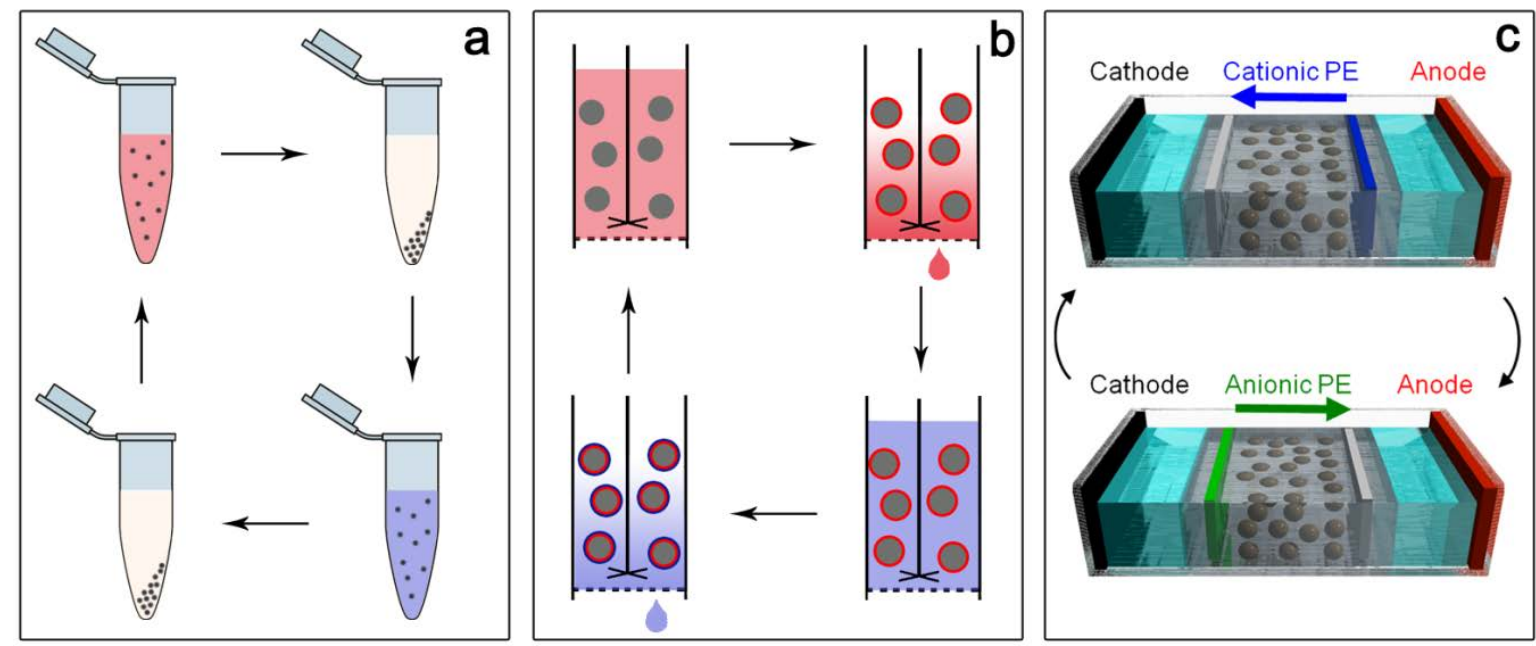

Fig. 2. Schematic representation of LbL assembly of polymer capsules with different approaches: (a) Centrifugation; (b) Filtration; and (c) Electrophoretic polymer assembly. Adapted with permission from Ref. [66]. Copyright 2013 WILEY-VCH Verlag GmbH \& Co. KGaA. 

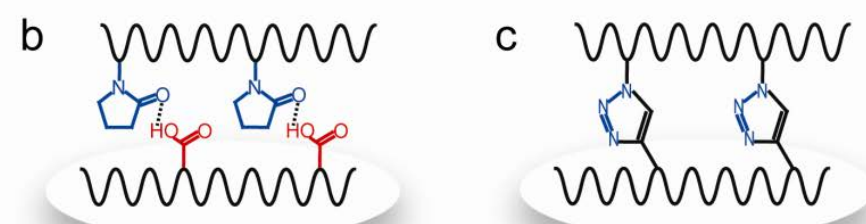

hydrogen bonding covalent bonding
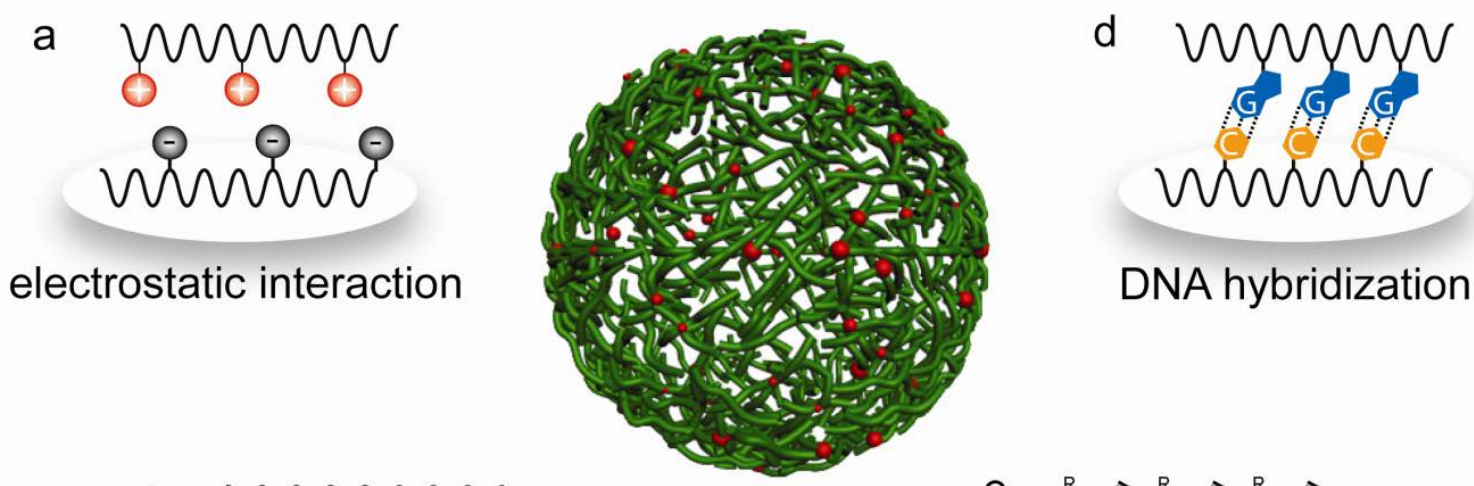

DNA hybridization

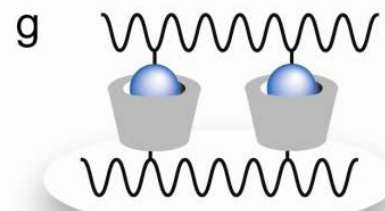

e

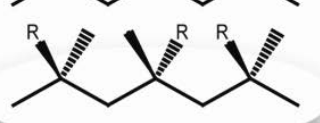

host-guest interaction

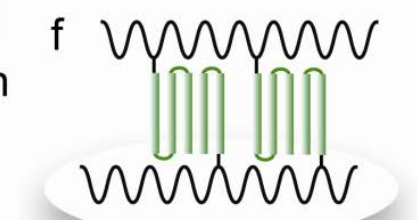

stereocomplexation

hydrophobic interaction

Fig. 3. Different polymer interactions for the assembly of multilayer capsules (centre). Interactions clockwise from left: (a) electrostatic; (b) hydrogen bonding; (c) covalent bonding; (d) DNA hybridization; (e) stereocomplexation; (f) hydrophobic; and (g) host-guest interactions. 


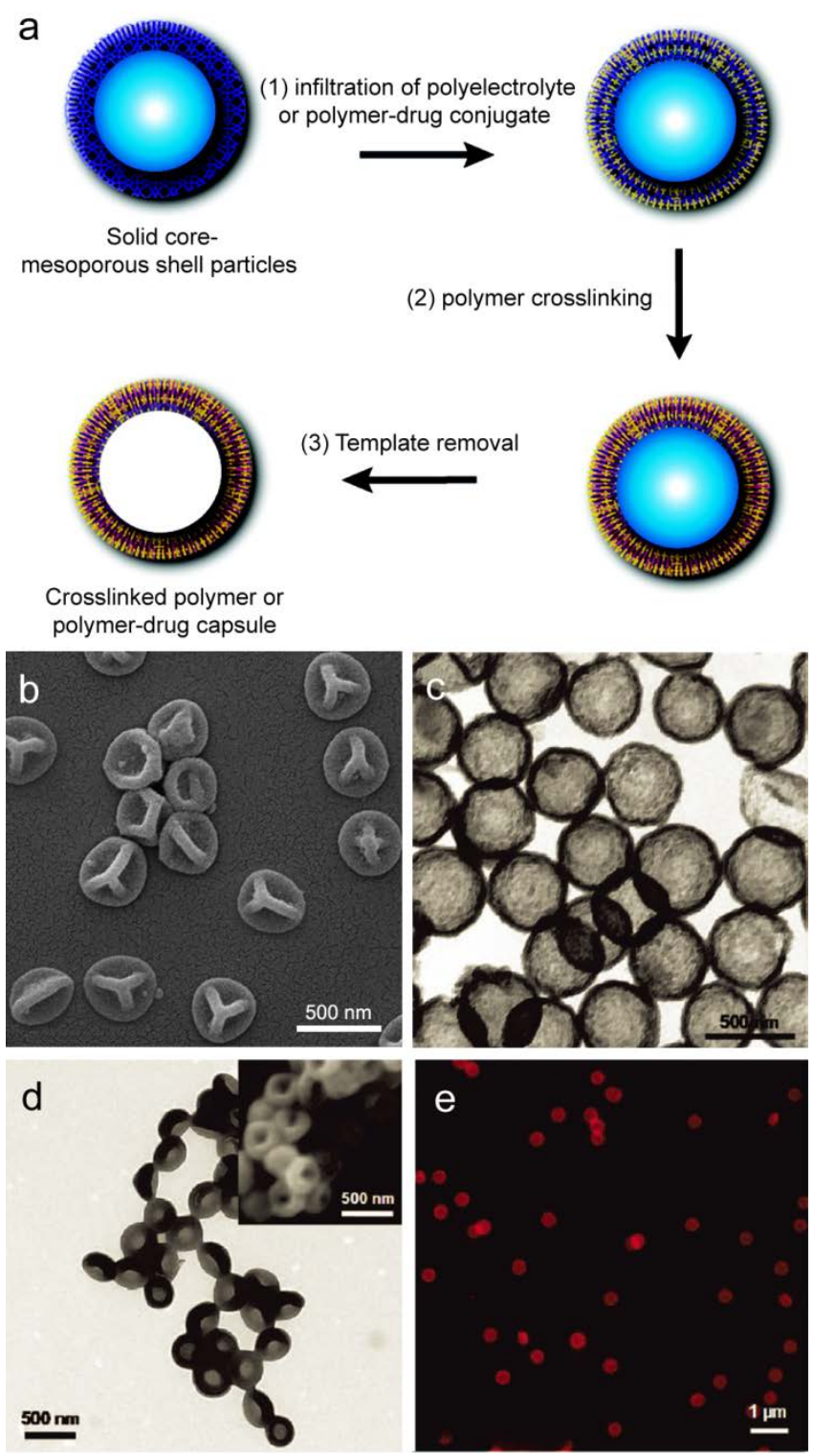

Fig. 4. (a) Schematic representation of the preparation of single-component polymer capsules by using SC/MS particles as templates. (b) SEM image of PAH nanocapsules. (c) TEM image of PLL nanocapsules. (d) TEM and (e) fluorescence microscopy images of PGA-Dox nanocapsules. Adapted with permission from Ref. [151]. Copyright 2008 American Chemical Society. 


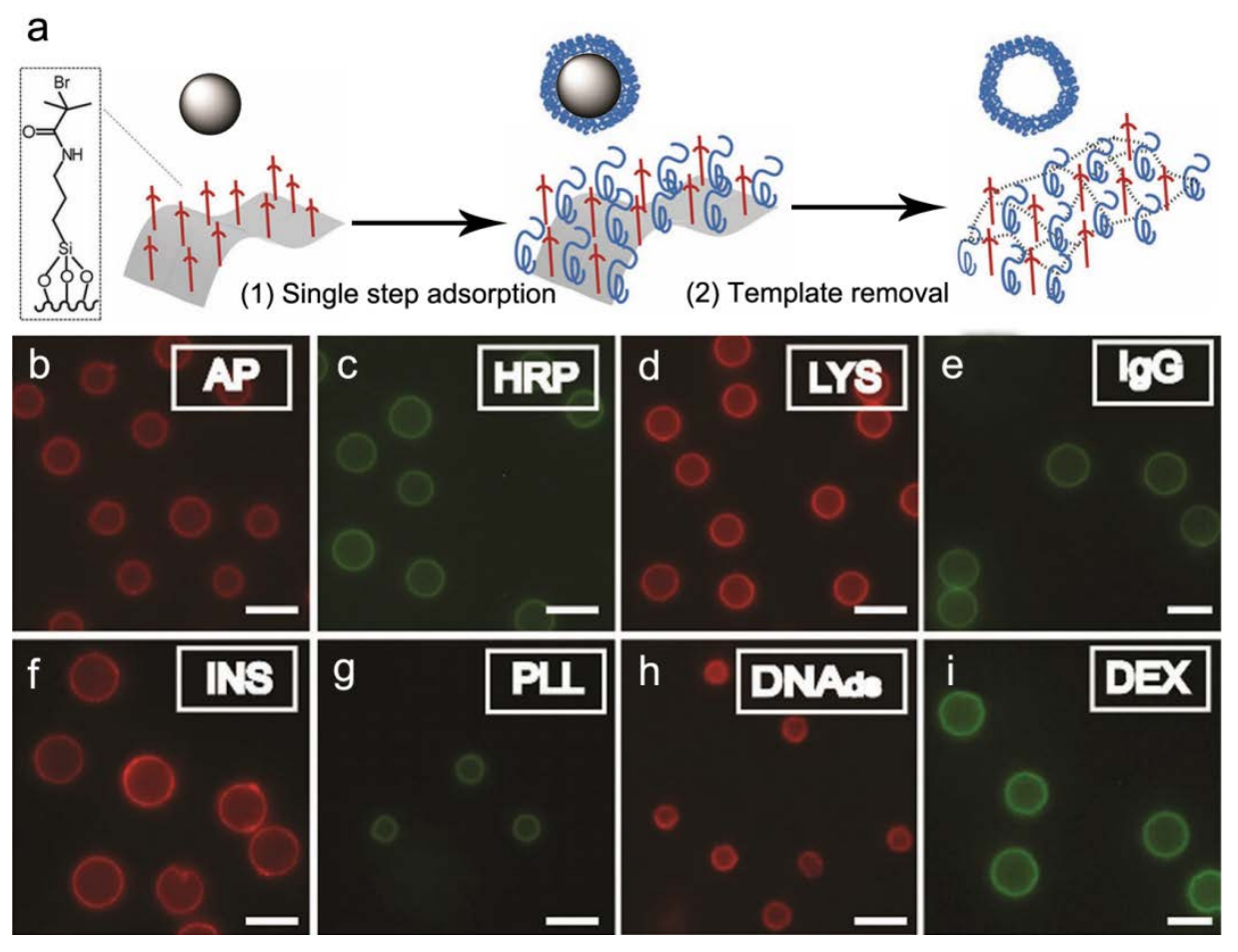

Fig. 5. (a) Single-step adsorption of a biopolymer (e.g., polypeptide, protein, nucleic acid or polysaccharide) from aqueous solution onto BrIBAM-modified silica templates followed by template removal yields the formation of free-standing biopolymer capsules. Fluorescence

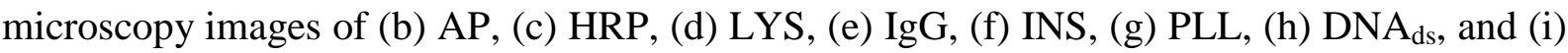
DEX capsules. RITC- or FITC-labeling results in red and green fluorescence, respectively. Scale bars are $5 \mu \mathrm{m}$. Adapted with permission from Ref. [156]. Copyright 2011 WILEYVCH Verlag GmbH \& Co. KGaA. 

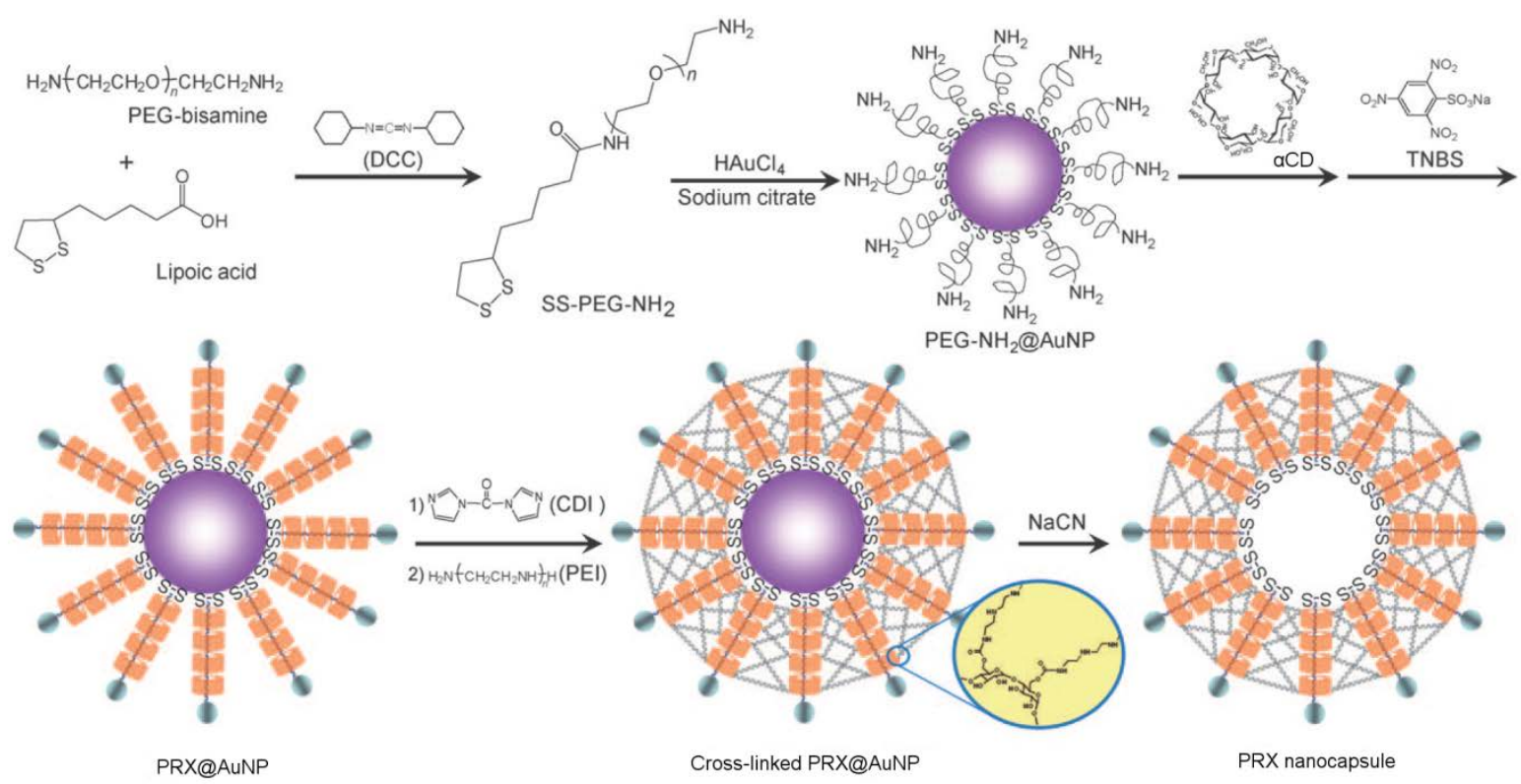

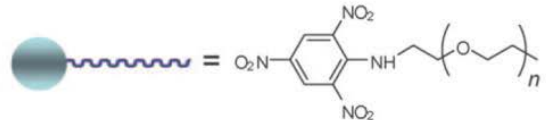

PEG chain with TNB end cap
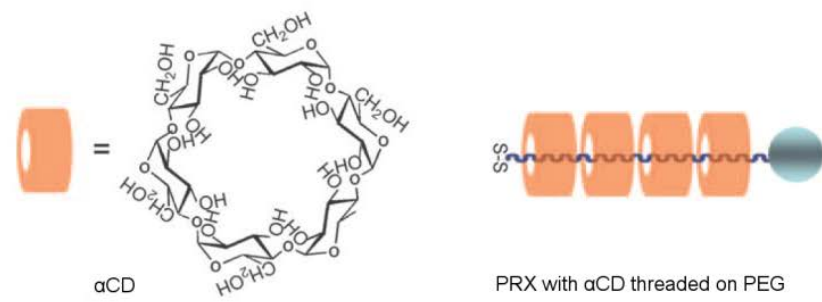

Fig. 6. Assembly of PRX nanocapsules by radial assembly from PEG functionalized AuNPs. Crosslinking was achieved by activation of the $\alpha \mathrm{CD}$ hydroxyl groups followed by reaction with PEI. Adapted with permission from Ref. [167]. Copyright 2009 WILEY-VCH Verlag GmbH \& Co. KGaA. 


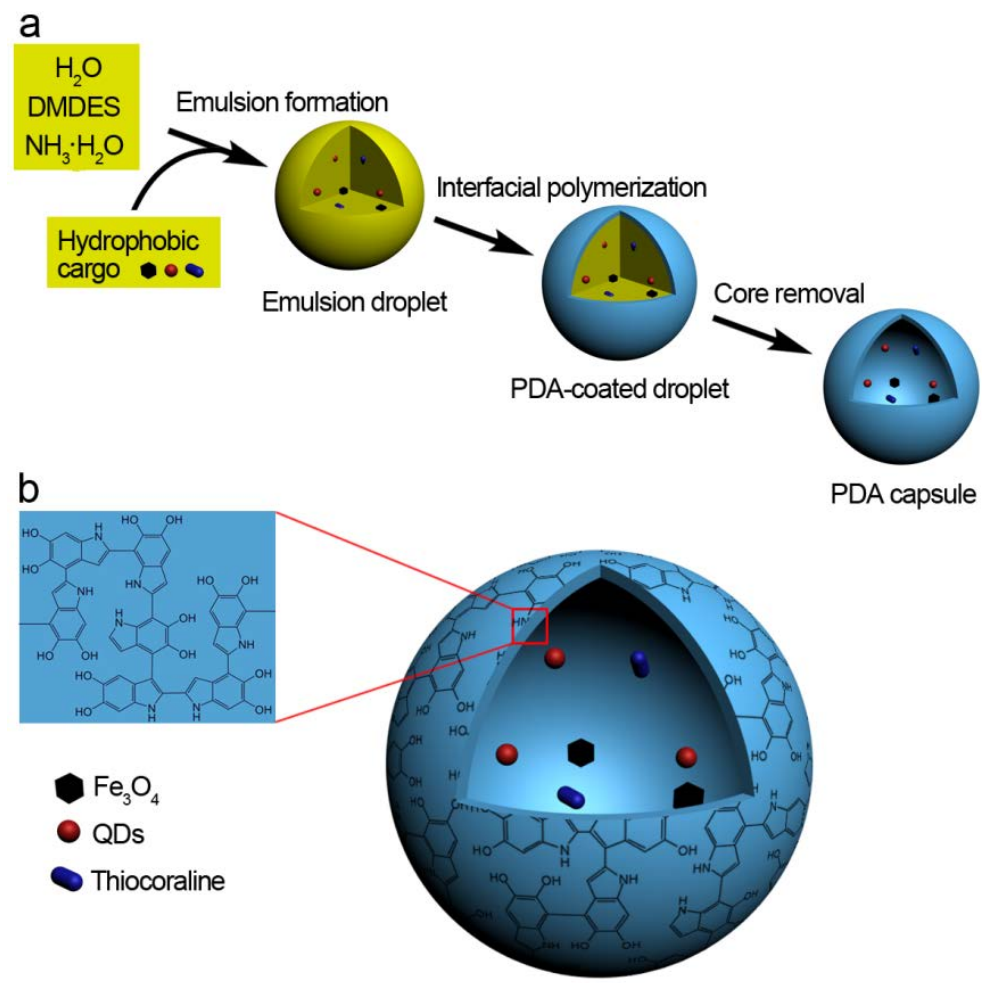

Fig. 7. (a) Schematic representation of the encapsulation of hydrophobic species in PDA capsules using DMDES emulsion templates. (b) An enlarged schematic of a loaded PDA capsule. Adapted with permission from Ref. [176]. Copyright 2010 WILEY-VCH Verlag GmbH \& Co. KGaA. 


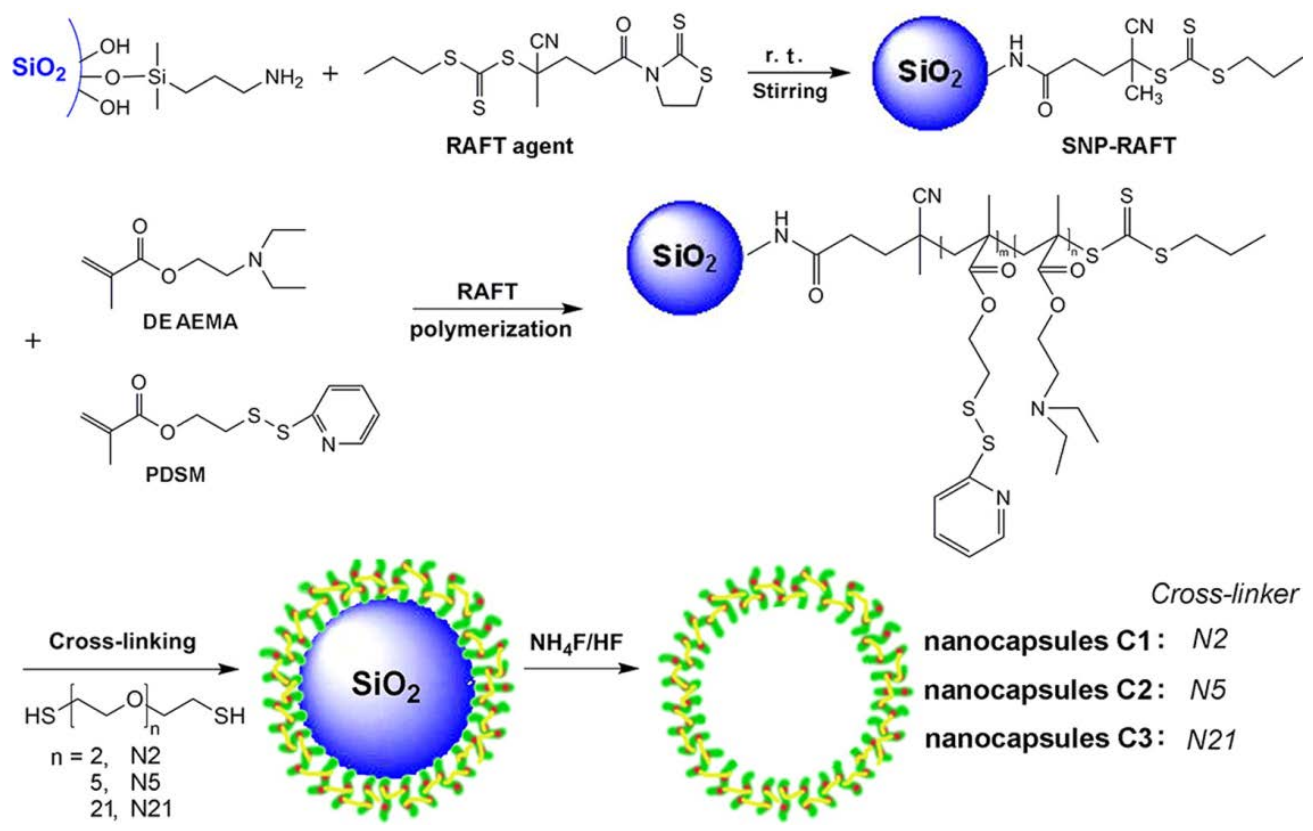

Fig. 8. Schematic for the assembly of dual-responsive (pH and redox) polymer capsules via SI-RAFT polymerization from aminated silica templates. Reproduced with permission from Ref. [195]. Copyright 2012 American Chemical Society. 
a
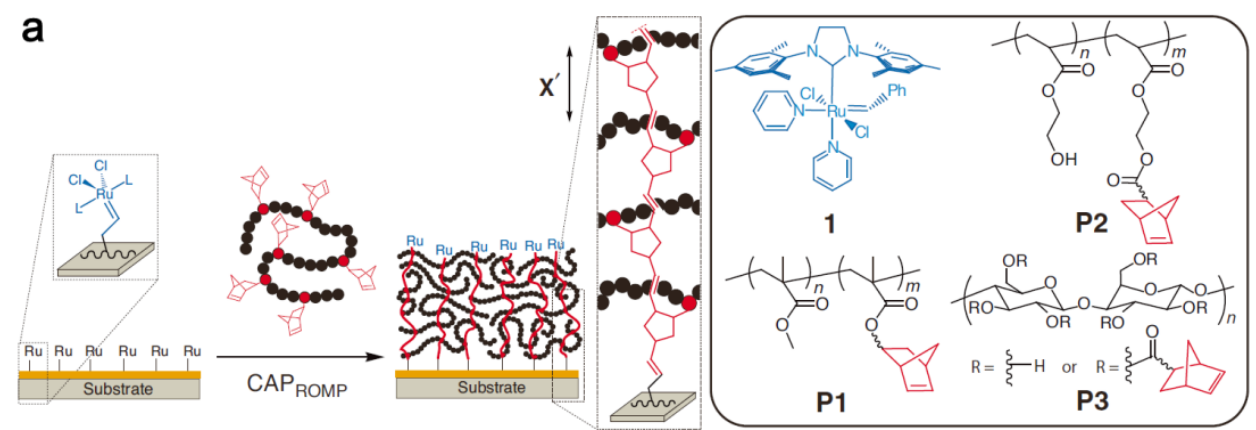

b

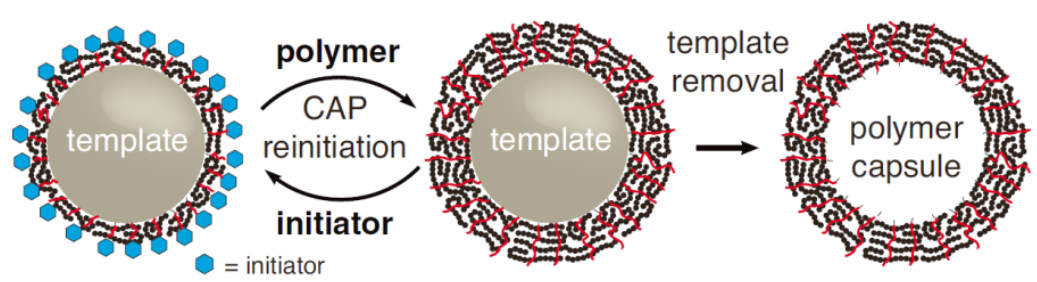

Fig. 9. (a) Schematic of film formation via the $\mathrm{CAP}_{\mathrm{ROMP}}$ process on a planar substrate. Surface initiator functionalization is achieved using catalyst $\mathbf{1}$ followed by the CAP $\mathrm{ROMP}_{\mathrm{P}}$ reaction with either $\mathbf{P 1}, \mathbf{P} 2$ or $\mathbf{P} 3$ macrocross-linkers. $\mathbf{X}^{\prime}$ represents the interlayer spacing. (b) Schematic of capsule formation via $\mathrm{CAP}_{\mathrm{ROMP}}$. Increased layer build-up was achieved by

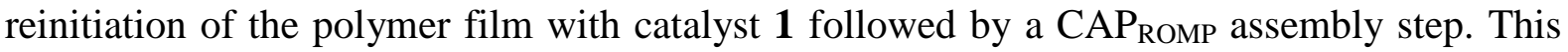
process was repeated until the desired film thickness was achieved followed by core removal. Adapted with permission from Ref. [196]. Copyright 2011 WILEY-VCH Verlag GmbH \& Co. KGaA. 


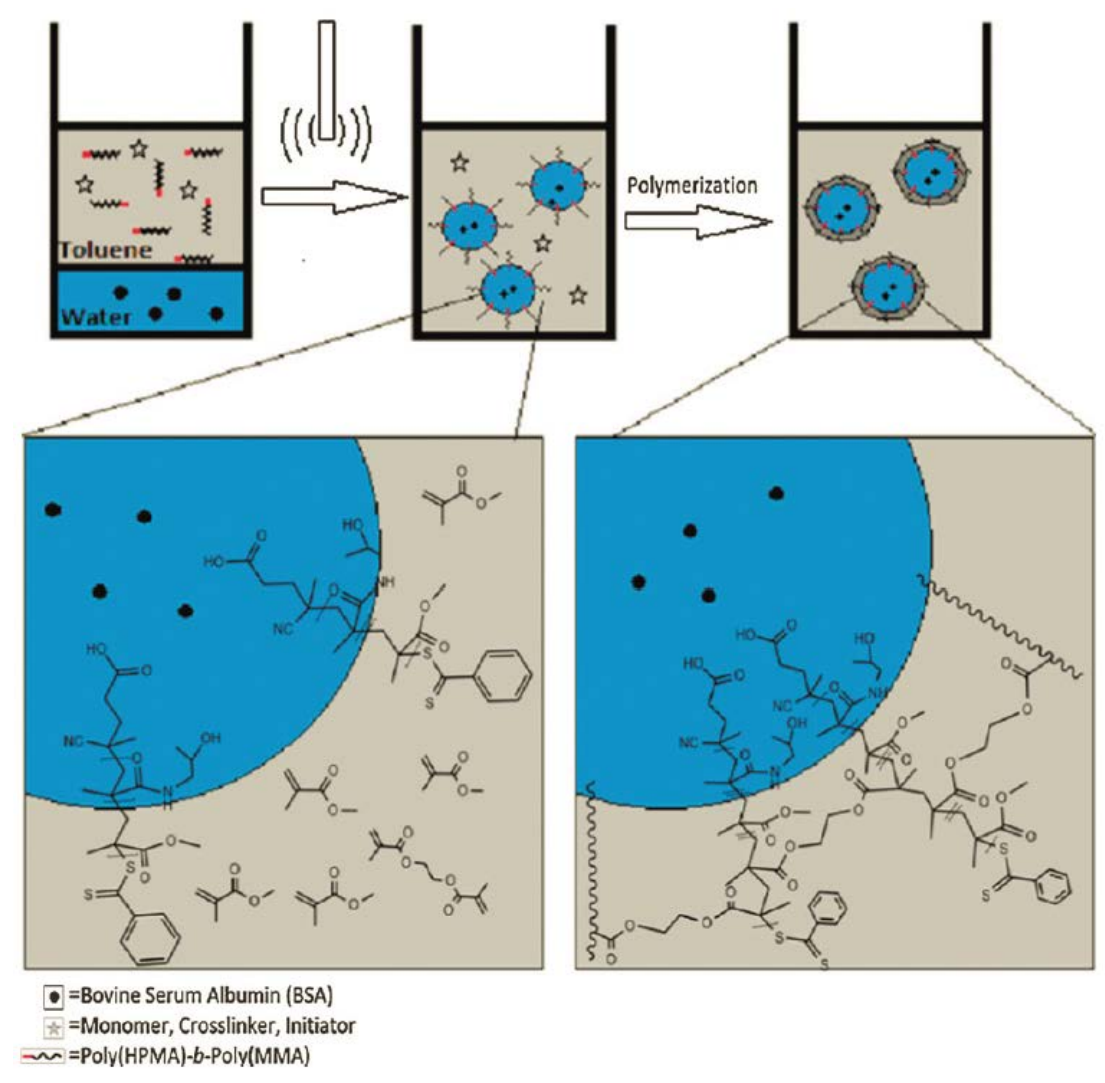

Fig. 10. Schematic of hollow protein-loaded polymer capsule assembly by IMEPP using poly(HPMA- $b$-MMA) as the surface-active RAFT agent. Reproduced with permission from Ref. [222]. Copyright 2012 The Royal Society of Chemistry. 

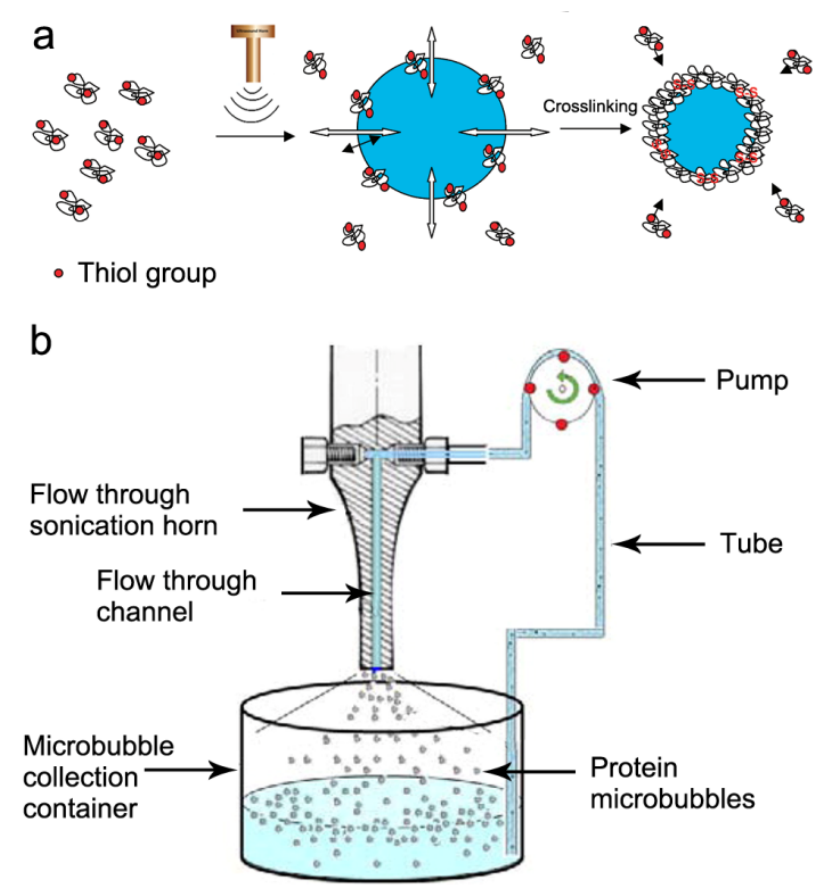

Fig. 11. (a) Proposed mechanism for the formation of disulfide cross-linked air-filled polymer microcapsules. (1) Emulsification of the amphiphilic polymer nanoaggregates induced by high energy ultrasound. (2) Diffusion of the polymer nanoaggregates to the interface. (3) Disulfide bridge formation between polymer nanoaggregates adsorbed at the air/water interfaces. Adapted with permission from Ref. [225]. Copyright 2008 American Chemical Society. (b) Schematic representation of the formation of microcapsules using the flow through sonication cell. Adapted with permission from Ref. [228]. Copyright 2012 American Chemical Society. 
$=0$ 


\section{University Library}

\section{- M M N E R VA A gateway to Melbourne's research publications}

Minerva Access is the Institutional Repository of The University of Melbourne

Author/s:

Cui, J;van Koeverden, MP;Muellner, M;Kempe, K;Caruso, F

Title:

Emerging methods for the fabrication of polymer capsules

Date:

2014-05-01

Citation:

Cui, J., van Koeverden, M. P., Muellner, M., Kempe, K. \& Caruso, F. (2014). Emerging methods for the fabrication of polymer capsules. ADVANCES IN COLLOID AND INTERFACE SCIENCE, 207 (1), pp.14-31. https://doi.org/10.1016/j.cis.2013.10.012.

Persistent Link:

http://hdl.handle.net/11343/123266 